\title{
on clouds
}

Varaha Ravi Kiran ${ }^{1}$, Madineni Venkat Ratnam ${ }^{1}$, Masatomo Fujiwara ${ }^{2}$, Herman Russchenberg ${ }^{3}$, Frank G

6 Wienhold ${ }^{4}$, Bomidi Lakshmi Madhavan ${ }^{1}$, Mekalathur Roja Raman ${ }^{5}$, Renju Nandan ${ }^{1}$, Sivan Thankamani

7 Akhil Raj ${ }^{1}$, Alladi Hemanth Kumar ${ }^{1}$, Saginela Ravindra Babu ${ }^{1}$

$8 \quad{ }^{1}$ National Atmospheric Research Laboratory (NARL), Gadanki, 517 112, India

$9 \quad{ }^{2}$ Faculty of Environmental Earth Science, Hokkaido University, Sapporo, 060-0810, Japan

$10{ }^{3}$ Department of Geoscience and Remote Sensing, Delft University of Technology, Delft, 2628CD, The Netherlands

$11{ }^{4}$ Institute of Atmospheric and Climate Science (IAC), Universitaetstrasse 16, Zurich, 8092, Switzerland

$12{ }^{5}$ Department of Physics, Sri Venkateswara University, Tirupati, 517 502, India 


\section{Abstract.}

Better understanding of aerosol-cloud interaction processes is an important aspect to quantify the role of clouds and aerosols in the climate system. There have been significant efforts to explain the ways aerosols modulate cloud properties. However, from the observational point of view, it is indeed challenging to observe and/or verify some of these processes because no single instrument or platform is proven sufficient. With this motivation, a unique set of observational field campaigns named Balloon borne Aerosol Cloud Interaction Studies (BACIS) is proposed and conducted using balloon borne in-situ measurements in addition to the ground-based (Lidars, MST radar, LAWP, MWR, Ceilometer) and space borne (CALIPSO) remote sensing instruments from Gadanki $\left(13.45^{\circ} \mathrm{N}, 79.2^{\circ} \mathrm{E}\right)$. So far, 15 campaigns have been conducted as a part of BACIS campaigns from 2017 to 2020. This paper presents the concept of observational approach, lists the major objectives of the campaigns, describes the instruments deployed, and discusses results from selected campaigns. Consistency in balloon borne measurements is assessed using the data from simultaneous observations of ground-based, space borne remote sensing instruments. A good agreement is found among multi-instrumental observations. Balloon borne in-situ profiling is found to complement the information provided by ground-based and/or space borne measurements. A combination of the Compact Optical Backscatter AerosoL Detector (COBALD) and Cloud Particle Sensor (CPS) sonde is employed for the first time to discriminate cloud and aerosol in an in-situ profile. A threshold value of COBALD color index (CI) for ice clouds is found to be between 18 and 20 and $\mathrm{CI}$ values for coarse mode aerosol particle range between 11 and 15 . Using the data from balloon measurements, the relationship between cloud and aerosol is quantified for the liquid clouds. A statistically significant slope (aerosol-cloud interaction index) of 0.77 (0.86) found between aerosol back scatter from $300 \mathrm{~m}(400 \mathrm{~m})$ below the cloud base and cloud particle count within the cloud indicates the role of aerosol in the cloud activation process. In a nutshell, the results presented here demonstrate the observational approach to quantify aerosol-cloud interactions and paves the way for further investigations using the approach.

\section{Introduction}

Understanding the fundamental process of aerosol-cloud interactions remains to be a challenging issue in the scientific community, already for more than three decades (Seinfeld et al., 2016). First ever observational evidence from analysis of ship tracks using satellite imagery had open up a wide scope for further research in this area (Coakley et al., 1987; Radke et al., 1989). Since then, efforts are underway using different observational and modeling techniques and lead to a significant development in the process based understanding, quantification and modeling (Abbott and Cronin, 2021; Fan 
et al., 2018; Haywood and Boucher, 2000; Koren et al., 2010; Lohmann, 2006; Lohmann and Feichter, 2004; Rosenfeld et al., 2008, 2014b). Despite of all these efforts, radiative forcing estimates due to aerosol-cloud interactions still show large uncertainties (IPCC, 2013). Apart from this, climate model simulations have uncertainties due to the fact that parameterization schemes are inefficient in representing the ways aerosols interact with clouds (Fan et al., 2016; Rosenfeld et al., 2014b; Seinfeld et al., 2016). At process level, various hypothesis have been proposed subsequent to the first indirect effect which was proposed almost four decades ago (Twomey, 1977). All these effects are found to act specific to cloud based on background meteorological, dynamical conditions. For example, the invigoration effect is proposed for convective clouds (Rosenfeld et al., 2014a) under the influence of updrafts. First indirect effect (Twomey effect) and second indirect effect (Albrecht effect) for liquid clouds have been shown to be influenced by mixing (Costantino and Bréon, 2010), turbulence and entrainment (Jose et al., 2020; Schmidt et al., 2015; Small et al., 2009). Although the first indirect effect is reasonably well understood, observational limitation poses serious challenges in understanding and/or evaluating other hypotheses.

Among the various observational techniques that are currently available (ground-based, space borne remote sensing and aircraft or unmanned ariel vehicle; UAV), none of the single observational technique has been proven self-sufficient in aerosol-cloud interaction studies. For example, ground-based (and/or space-borne) lidars suffer serious attenuation and even losses of observations due to the presence of optically thick cloud layers in the atmosphere. Thus, they may not be able to represent the complete vertical structure of cloud and aerosols. Note that information on aerosol/cloud profile is essential for the estimation of their climate effects. Similarly, satellite data analysed with different analytical methods such as by changing grid resolutions have shown different results and conclusions (Grosvenor et al., 2018; Koren et al., 2010;

McComiskey and Feingold, 2012). Besides this, in-situ measurements using aircraft and UAV have been remarkable in obtaining detailed information on the microphysics of cloud and aerosol (Corrigan et al., 2008; Kulkarni et al., 2012; Redemann et al., 2020; Weinzierl et al., 2017). However, there are serious limitations with respect to altitude coverage, feasibility of conducting aircraft or UAV campaigns and overall cost involved. Also, there is a chance that the aircraft perturb the atmosphere before it actually makes the measurement of cloud/aerosol. 

techniques so as to obtain a comprehensive picture. A classic paper by Feingold et al. (2003) first time quantified the 'Twomey effect' using ground-based remote sensing instruments such as a micro-wave radiometer (MWR), cloud radar and

87 a Raman Lidar. In an intensive operations program, Feingold et al. (2006) conducted airborne in-situ measurements for obtaining the cloud effective radius using an aircraft in addition to the ground-based and space borne remote sensing instruments. Pandithurai et al. (2009) also quantified the 'Twomey effect' using a suite of ground-based remote sensing instruments (cloud radar, MWR, polarization Lidar) along with the surface aerosol measurements (aerosol size distribution, scattering coefficient and cloud condensation nuclei concentration). Similarly, Sena et al. (2016) utilized 14 years of coincident observations from cloud radar and a laser Ceilometer along with surface reaching shortwave radiation measurements from the Atmospheric Radiation Measurement (ARM) program over the Southern Great Plains, USA to investigate aerosol modifications on cloud macroscopic parameters and radiative properties rather than cloud microphysical parameters. In addition to simultaneous measurements of cloud/aerosol, concurrent measurements of thermodynamic and dynamic parameters of the atmosphere are also needed to thoroughly understand the process of aerosol-cloud interactions. A step forward in this direction, McComiskey et al. (2009) used long term, statistically robust ground-based remote sensing data from Pt. Reyes, California, USA to not only quantify the 'Twomey effect' but also examine the factors influencing the variability in aerosol indirect effects such as updraft velocity, liquid water path, scale and resolution of observations. Using a novel dual field of view Raman Lidar and a Doppler Lidar technique, Schmidt et al. (2014) analysed the data from Leipzig, Germany to explore linkages between aerosol and cloud properties, the influence of updrafts. Sarna and Russchenberg, (2016) used synergy of measurements from a Lidar (Ceilometer), Radar (cloud radar) and a Radiometer (MWR) collected at ARM Mobile facility at Graciosa Island, the Azores, Portugal and at the Cabaw Experimental Site for Atmospheric Research (CESAR) observatory, The Netherlands, to not only quantify the aerosol indirect effect but also attempted to disentangle the effect of vertical wind (Sarna and Russchenberg, 2017). All these studies contributed significantly to the knowledge on aerosol-cloud interactions but are based on remote sensing techniques, limited to the low-level, warm and non-precipitating clouds only. 
In view of the measurement limitations discussed above, a balloon borne in-situ measurement is suggested to be the

109 best complimentary technique as balloons can pass through the cloud (during their ascent/descent) representing the vertical

110

111

112

113

114

115

116

117

118 structure of the cloud as well as aerosol below and above the cloud near simultaneously (see Sect. 2 for details) without perturbing the atmosphere. Information from balloon borne in-situ measurements in combination with the ground-based and/or space borne platforms will be of great help in constructing the complete vertical profiles of aerosol, cloud and further understanding the process of aerosol-cloud interactions. With this in mind, a balloon borne field campaign named BACIS (Balloon borne Aerosol Cloud Interaction Studies) was initiated in the year 2017 from National Atmospheric Research Laboratory (NARL), Gadanki (13.45 N, 79.2 E), India, with multi-instrumental approach. Gadanki located in Southern Peninsular India is influenced by both the South West and North East Monsoon. Most importantly the location hosts a suit of unique ground-based instruments that cover optical, radio and in-situ techniques. A combination of specialized sondes like the Compact Optical Backscatter AerosoL Detector (COBALD; see https://iac.ethz.ch/group/atmosphericchemistry/research/ballon-soundings.html, last access: 19 June 2021) and the Cloud Particle Sensor (CPS; Fujiwara et al., 2016) are used together for the first time in the present study.

The concept of observational strategy, objectives of the campaign and details about the balloon sensors, ground/space based instruments, data processing, interpretation of data are provided in the second section. The third section discusses the results on consistency in multi-instrumental observations, interpretation of aerosol and cloud features in a profile, multiple soundings to estimates statistics on threshold values of aerosol/cloud and finally illustrates the relationship between aerosol-cloud relationships. The fourth section summarizes the results.

\section{Instruments and methodology}

\subsection{Balloon borne sensors}

\subsubsection{COBALD}

The Compact Optical Backscatter AerosoL Detector (COBALD) deployed in BACIS campaigns is a lightweight (540 g) balloon borne sonde developed in the group of Professor Thomas Peter at ETH Zurich, Switzerland. It is essentially a miniaturized version of backscatter sonde developed by Rosen and Kjome (1991). The COBALD consists of two LED light sources of approximately $500 \mathrm{~mW}$ power emitting $455 \mathrm{~nm}$ (blue) and $940 \mathrm{~nm}$ (termed 'infrared') wavelengths, respectively 
133 (Brabec et al., 2012). The light emitted by the sonde illuminates the air in the vicinity, and backscattered light is detected

134 using a silicon photo detector. The emitted beams divergence (4 degrees FWHM), detector field of view (6 degrees) and geometrical alignment of optics yields reception of backscatter light from a distance of $0.5 \mathrm{~m}$ (overlapping distance) from the sonde. The region of up to $10 \mathrm{~m}$ from the instrument contributes to $90 \%$ of the measured backscattering signal. The realtime backscatter data, in units of counts per seconds (cps, originating from the internal data treatment) is included in the radiosonde telemetry at a frequency of $1 \mathrm{~Hz}$ and sent to the ground station along with the pressure and temperature measurements. In the present case, we have used an iMet radiosonde (InterMet, USA). The sondes were usually operated for about 15 minutes at the surface (before launch) for thermal stabilization, verified by cross-checking the LED brightness monitor signals, also delivered in cps, with sonde specific reference values provided by the manufacture. The sonde is passed when the return signal data is within $15 \%$ of the reference value.

\subsubsection{CPS}

Cloud Particle Sensor (CPS) sonde is a light weight balloon borne sensor ( 200 g) developed for the detection of cloud particle number and phase (Fujiwara et al., 2016). The latest version of the sonde (launched in the campaigns) is supplied by Meisei Electric Corporation, Japan, along with a Meisei RS-11G radiosonde (Kobayashi et al., 2019; RS$11 \mathrm{G}(\mathrm{R} 3)$ is the model with an interface for CPS). CPS primarily consists of a column $(\sim 1 \mathrm{~cm} \times 1 \mathrm{~cm}$ in cross-section and $\sim 12 \mathrm{~cm}$ in vertical length) for air passage, a diode laser $(\sim 790 \mathrm{~nm}$, polarized) and two silicon photo detectors. Cloud particles entering the column due to the balloon ascent are illuminated by the laser. The scattered light from cloud particles is detected by the photo detectors placed at an angle of $55^{\circ}$ and $125^{\circ}$ to the incident laser light. The detector at $125^{\circ}$ comes with an additional polarization plate positioned in front of it for the detection of cross-polarization whereas the detector at $55^{\circ}$ measures the intensity of plane-polarized scattered light. The intensities I55 and I125, for the detectors located at $55^{\circ}$ and $125^{\circ}$, respectively, are provided in voltage, and I55 is related to particle size. The minimum size of a water droplet that can be detected by CPS is found to be $2 \mu \mathrm{m}(1 \mu \mathrm{m}$ particles are undetected in laboratory experiments using various standard spherical particles) and 55 was found to sometimes saturate $(\sim 7.5 \mathrm{~V})$ for particles $\sim 80-140 \mu \mathrm{m}$ (Appendix A of Fujiwara et al., 2016). Real time data from CPS is transferred to the ground station through RS-11G(R3) radiosonde at a frequency of 1Hz. CPS data include number of particles counted in a sec, scatted light intensity (in Voltage) for the two detectors (I55 and 

information is transmitted to the ground station only for the first six particles for each second due to the limited downlink rate of RS-11G which is 25 byte $\mathrm{s}^{-1}$. Before launch, the sonde is tested by spraying water near to air passage column for particle detection.

\section{2.2. Remote sensing instruments}

163

\subsubsection{MPL}

A Micro Pulse Lidar (MPL) was operated on 07-08 July 2017 during first two campaigns. However, a laser Ceilometer (make of Vaisala, Finland) was made available for the rest of the campaigns due to non-availability of MPL. Complete technical details of MPL used in the campaign can be found in Cherian et al. (2014). A low energy $(<10 \mu \mathrm{j})$ green $(532 \mathrm{~nm})$ pulsed laser of pulse width less than $10 \mathrm{~ns}$ were shot from MPL at a pulse repetition frequency of $2500 \mathrm{~s}^{-1}$. A Cassegrain type telescope of $150 \mathrm{~mm}$ diameter and a PMT have been deployed to collect the backscattered photons (copolarized) from particles and clouds in the atmosphere. The entire system is operated at a dwell time of $200 \mathrm{~ns}$ which would correspond to range resolution of $30 \mathrm{~m}$. The return signals were collected for 1500 bins which correspond to the total range of $45 \mathrm{~km}$. A profile of backscattered photons was obtained for every $300 \mu \mathrm{s}$ and all profiles collected were averaged for every one minute. The telescope field of view and laser beam divergence coincides or overlap at above $\sim 150 \mathrm{~m}$. Using the data from MPL (from Gadanki and the nearby location at Sri Venkateswara University, Tirupati, India $\left(13.62^{0} \mathrm{~N}, 79.41^{0} \mathrm{E}\right.$; $\sim 35 \mathrm{~km}$ from Gadanki), Ratnam et al. (2018) reported the presence of an elevated aerosol layer in the lower troposphere ( 3 $\mathrm{km}$ ) during South-West Monsoon Season and discussed the possible causes for the formation and maintenance of this elevated layer. The low level jet (LLJ) between 2 and $3 \mathrm{~km}$ in the lower troposphere present during South West Monsoon causes formation of elevated layer. In addition, the presence of shear between LLJ and tropical easterly jet (TEJ) maintains the elevated layer restricting upliftment of aerosol. Prasad et al. (2019) also used the same dataset to discuss nocturnal, seasonal and intra-annual variation in the tropospheric aerosol. A laser Ceilometer (operated in rest of the campaigns) is similar to a MPL but operates at $910 \mathrm{~nm}$ wavelength and provides round the clock measurements of cloud base heights, boundary layer height apart from aerosol extinction under all weather conditions (Wiegner et al., 2014).

\subsubsection{Mie Lidar}


184 This lidar was operated in almost all the campaigns. A very high energy $(600 \mathrm{~mJ})$ pulsed laser of pulse width of less than 7 $\mathrm{ns}$ and a pulse repetition frequency of $50 \mathrm{~s}^{-1}$ is operated at a wavelength of $532 \mathrm{~nm}$. A $320 \mathrm{~mm}$ diameter Cassegrain type telescope along with a couple of PMT has been used as a detection assembly to collect the co and cross-polarized return signal. However, the co-polarization channel (only) is analysed in the present study. The data is stored at a dwell time of $2 \mu \mathrm{s}$ which corresponds to the range resolution of $300 \mathrm{~m}$ and the profiles collected were averaged for every $250 \sec (\sim 4 \mathrm{~min})$. The data is considered to be reliable from an altitude of 3-4 $\mathrm{km}$ as the field of view of Mie telescope and laser beam divergence overlap at this height (Pandit et al., 2014). For the first time, sixteen years of Mie lidar data has been analysed to determine the long-term climatology of tropical cirrus clouds (Pandit et al., 2015). Gupta et al. (2021) reported the long-term observations of aerosol extinction profiles using combination of MPL, Mie lidar and space borne CALIPSO lidar.

\subsubsection{CALIPSO}

Cloud Aerosol Lidar with Orthogonal Polarization (CALIOP) is the space born lidar on board CALIPSO satellite (L'Ecuyer, 2011). CALIOP consists of two pulsed diode lasers operating at 532 and $1064 \mathrm{~nm}$ wavelengths with pulse energy of $110 \mathrm{~mJ}$ and a repetition rate of $\sim 20 \mathrm{~Hz}$. Backscattered signal is collected by an avalanche photo diode (APD) at $1064 \mathrm{~nm}$ and photo multiplier tubes (PMT) at $532 \mathrm{~nm}$. The signals at $532 \mathrm{~nm}$ are collected at both parallel and perpendicular to the plane of polarization of outgoing beam, while for $1064 \mathrm{~nm}$ channel polarization is parallel only. The range resolution of the backscattered profile at $532 \mathrm{~nm}$ is $30 \mathrm{~m}$ for the altitude range from -0.5 to $8.2 \mathrm{~km}, 60 \mathrm{~m}$ for 8.2 to $20.2 \mathrm{~km}$ and $180 \mathrm{~m}$ for $>20-30 \mathrm{~km}$. Horizontal resolution is $0.33 \mathrm{~km}$ for -0.5 to $8.2 \mathrm{~km}$ and $1 \mathrm{~km}$ for $8.5-20.2 \mathrm{~km}$. More details about CALIOP can be found in Winker et al. (2007).

\subsubsection{MST Radar}

The Indian MST radar located at Gadanki is high-power coherent backscatter VHF (Very High Frequency) radar operating at 53MHz. The detailed description of MST radar can be found in Rao et al. (1995). Before the BACIS campaign, it has been upgraded to a fully active phased array with dedicated $1 \mathrm{~kW}$ solid state transmitter-receiver units (total power of $1024 \mathrm{~kW}$ ). This radar operates in Doppler Beam Swinging (DBS) mode to provide wind information covering the troposphere, lower stratosphere and mesosphere. Atmospheric scatterers are advected with the background air motions and 
the three-dimensional wind velocity vectors (zonal, meridional and vertical) can be directly deduced from the Doppler shifts

of the radar echoes received in three independent beam directions. Note that these radars are the only means of getting direct vertical velocities presently and plays a crucial role in the understanding of aerosol-cloud interaction processes. For the present study, data is obtained from five beam directions with 256 FFT (Fast Fourier Transform) points and coherent integrations, 4 incoherent integrations, Inter Pulse Period (IPP) of $160 \mathrm{~ms}$, pulse width of $8 \mu$ s coded covering the altitude region of 3 to $21 \mathrm{~km}$ with $150 \mathrm{~m}$ vertical resolution.

\subsection{The observational concept of BACIS Campaign}

A unique observational approach is proposed here wherein a balloon borne in-situ measurement is made simultaneously while the multiple remote sensing instruments are operational from the ground and space borne platforms. The schematic diagram shown in Figure 1 illustrates the entire concept. A meteorological balloon with specialized sondes such as COBALD (Brabec et al., 2012) and CPS (Fujiwara et al., 2016) along with a radiosonde is launched $~ 10-30$ minutes prior to CALIOP on board Cloud-Aerosol Lidar and Infrared Pathfinder Satellite Observation (CALIPSO; Winker et al., 2007) (night time) overpass close by Gadanki. Ground-based remote sensing instruments at NARL, Gadanki such as a Micro Pulse Lidar (MPL; Cherian et al., 2014) and/or a laser Ceilometer (Wiegner et al., 2014), a Mie Lidar (subsequently referenced to as 'Mie'; Pandit et al., 2014), an Indian MST Radar (Rao et al., 1995) and/or a Lower Atmospheric Wind Profiler (LAWP; Srinivasulu et al., 2012) are also operated before, during and after the launch. Other observational facilities such as ambient aerosol instruments at the Indian Climate Observatory Network (ICON), NARL, Gadanki and a MWR are operated during the launch period. Table 1 lists the ensemble of instruments used in the campaign, their purpose and the physical quantity that can be obtained from each instrument. Temporal variation of remote sensing data on cloud and aerosol profiles is obtained from ground-based (MPL/Mie) lidars. Space borne lidar (CALIPSO) also provides the same but for an along-track (roughly meridional) distribution near the time of overpass over Gadanki. On the other hand, in-situ measurements of aerosol and cloud profiles along with background meteorological parameters (temperature, relative humidity, wind speed and direction) are collected using the specialized balloon sounding (COBALD and CPS). Combined data from balloon, ground/space borne lidars are the basis for the identification of aerosol and cloud particles. Apart from 

and relative humidity profiles, etc., useful to constrain the cloud water content in a cloud layer to understand the aerosol influence on cloud properties. In addition to these measurements, surface aerosol information obtained by the instrumentation available at the ICON observatory, NARL helps in understanding the role of sources of aerosol from the surface. Altogether, near-simultaneous information on the aerosol, cloud and background meteorological conditions obtained from the multi-instruments is aimed to understand the aerosol-cloud interactions. months. However, due to the limited number of stock of specialized sondes (available with us), it was decided to conduct instead two pilot campaigns to demonstrate the concept proposed. Apart from this, it was also required to have balloon/payload tracking equipment to ensure the safe recovery of the payloads. A low-cost GPS/GSM based tracker was made available for this purpose. Subsequently, two pilot campaigns were conducted in the early hours of 6 June and 8 July 2017. Table 2 lists the date and time of all balloon campaigns that have been conducted from Gadanki as a part of BACIS campaigns and the instruments operated during the corresponding campaign. As shown in Table 2, so far 15 launches have been conducted from the year 2017 to 2020 .

Figure 2 shows the photographs taken at the balloon facility, NARL just before the launch during one of the campaigns. The balloon payload with specialized sondes (COBALD, CPS) and radiosonde (iMet and RS-11G) is shown in Fig. 2(a) and the prelaunch activities at the field are shown in Fig. 2(b). Skilled personnel were deployed for the launch and recovery of the payload. As of now, we have recovered all the launch payloads successfully (expect one) with the help of GPS/GSM tracker assembly. Except the two pilot campaigns, the rest of them were conducted during the nights irrespective of the CALIPSO satellite overpass as there was a maneuverer in CALIPSO orbit during September 2018 (CALIPSO track got departed from A-Train to join C-Train. More details can be found at link https://atrain.nasa.gov/), followed by which we could not find CALIPSO nighttime passage close by Gadanki. Apart from this, MPL measurements were not available after few initial campaigns due to the technical issues. However, a laser Ceilometer was operated in place of MPL. The other major issue for conducting a campaign was limited availability of specialized sondes and compatible radiosondes, GPS/GSM 
be seen from the Table 2, we have managed to operate all the essential instruments proposed in the observational approach during other campaigns. In particular, the campaigns in the year 2019 were conducted once in a month (March to June, 2019) or two months (July to December, 2019).

With the observational approach described above, the following scientific issues/objectives are being pursued/realized:

i. Demonstration of the potential of the multi-instrumental approach in obtaining the information on aerosol and cloud, associated environmental parameters, such as 3D-winds, relative humidity, temperature near simultaneously.

ii. Show consistency of balloon borne in-situ measurements among the combination of space borne and/or ground-based instruments.

iii. Discrimination of aerosol and cloud in a balloon sounding using the combined observations of COBALD and CPS sondes. This is a prerequisite to use balloon information for aerosol-cloud studies.

iv. Testing and quantification of aerosol-cloud interactions and understanding the influence of meteorological and dynamical parameters.

v. Find out the differences, if any, in the estimates of the magnitude of aerosol-cloud interaction using multi-instruments and discuss the possible reasons for the observed discrepancies.

273 vii. Assessment of model simulations using the multi-sensor data.

\subsection{Methods of data processing and interpretation}

\subsubsection{COBALD data processing}

Backscattered light received by COBALD is contributed from molecules, aerosols and cloud particles in the atmosphere. The molecular Rayleigh contribution to the raw signal (cps) is established during post-processing of the data using the simultaneous temperature and pressure recordings of the radiosonde. It serves to normalize the total signal in terms of backscattering ratio (BSR) according to

$$
B S R=\frac{\beta_{\text {total }}}{\beta_{\text {molecular }}}
$$

281 where $\beta_{\text {total }}$ and $\beta_{\text {molecular }}$ are the backscatter coefficient corresponds to the contribution from particles plus molecules and 

backscatter coefficient to the molecular one. The uncertainty in the COBALD BSR is estimated to be $1 \%$ and $5 \%$ at surface level and $10 \mathrm{~km}$, respectively (Brabec et al., 2012; Vernier et al., 2015). The Color Index (CI), referring to the particle backscatter only, is calculated from Equation 2.

$$
C I=\frac{B S R_{940}-1}{B S R_{455}-1}
$$

By definition $\mathrm{CI}$ is an independent quantity of particle number concentration and hence useful in interpreting the size of a particle. For analysis, COBALD raw data is binned in to $1 \mathrm{hPa}$ pressure levels. This could minimize noise, unwanted data and smoothening profile. Figure 3 shows a typical example of COBALD data collected during the second campaign (8 July 2017). BSR at $455 \mathrm{~nm}$ and $940 \mathrm{~nm}$ wavelength channels represented by blue and red colored lines, respectively, while CI (derived using Equation 2) is shown in green colored line. From Fig. 3, a sharp increase in all parameters (BSR at two channels, CI) found around $5 \mathrm{~km}$ associated with a thermal inversion (see temperature profile in Fig.3 in black color) may be attributed to the presence of a low-level cloud or elevated aerosol layer. Below $\sim 5 \mathrm{~km}$, the BSR profile indicates tropospheric aerosol distribution. Within this altitude, BSR values around $2 \mathrm{~km}$ indicate boundary layer confinement. Note no significant changes in CI within this $2 \mathrm{~km}$ height. Significant values in all parameters between 10 and $16 \mathrm{~km}$ are indicative of multiple high level cloud layers. In the rest of the campaigns, we have noticed that COBALD has captured profile information that was missing in lidar data.

\subsubsection{CPS data processing}

The phase of the cloud particle detected by CPS is determined using a quantity called degree of polarization (DOP) given by the following relation:

$$
D O P=\frac{I 55-I 125}{I 55+I 125}
$$

302 Since the spherical particles (water droplets) do not provide significant voltage in the cross-polarization (I125 close to 0), the DOP values for such particles would be close to 1 . On the other hand, the DOP for non-spherical particles (for example ice crystals) would take values between -1 and 1 randomly as I125 is non-zero and may or may not be greater than I55. Apart 305 from this, CPS can also detect the non-spherical particles in the lower troposphere whose DOP values may vary between -1 306 and 1. 
Fujiwara et al., 2016 for the details). Therefore, when the particle number concentration is greater than $\sim 2 \mathrm{~cm}^{-3}$, more than one particle would exist simultaneously in the detection area, resulting in particle overlap and multiple scattering and thus a counting loss. The counting loss occurrence can be identified using a house-keeping parameter called 'particle signal width' defined as the time taken for detection of a single particle. A simple correction of particle count using the particle signal width information is proposed by Fujiwara et al. (2016, see their section 2.3 for the details) using a factor 'f' which is (particle signal width in $\mathrm{ms}) /(1 \mathrm{~ms})$ as follows. The raw counts from a CPS are corrected for multiple scattering and overlap effects using particle signal width data using Equation 4.

$$
\mathrm{N}_{\text {corr }}=\mathrm{N}_{\text {meas }} \times 4 \mathrm{f}^{3}
$$

317 CPS detection area as 70\% of the balloon ascent rate (see Appendices B and C of Fujiwara et al., 2016). The uncertainty of 318 the number concentration when the above correction to the particle count is made (i.e., for the case of $>\sim 2 \mathrm{~cm}^{-3}$ ) has not 319 been evaluated by Fujiwara et al., 2016. It would be safe to assume that the estimated number concentration is valid in the representation of variations in the cloud property rather than magnitude. CPS data were analyzed at their actual resolution of $\sim 5 \mathrm{~m}$. Figure 4a shows the corrected cloud particle (number) count (based on eq. 4) for the same day as shown in fig.3. Significant cloud particle count is found at around $5 \mathrm{~km}$ and from above 10 to $16 \mathrm{~km}$. The number of particles counted per second at $5 \mathrm{~km}$ turn out to be high suggesting the presence of a dense (optically thick) layer of low-level cloud. The corresponding cloud particle number concentration $\left(\# / \mathrm{cm}^{3}\right)$ also represents (Fig. 4b) the cloud layers at same altitudes. The DOP is estimated as per Equation 3. In Fig. 4c, DOP values are found to be clustered in the region close to 1 at $\sim 5 \mathrm{~km}$, indicating that the dense (low) cloud layer is a liquid cloud. On the other hand, the DOP values are randomly distributed between -1 and 1 in the altitude region of $>10$ to $16 \mathrm{~km}$, indicating that these are ice clouds. In Fig. $4 \mathrm{~d}$ and $4 \mathrm{e}$, particle signal width is often greater than $1 \mathrm{~ms}$ and 155 is sometimes $\sim 7.5 \mathrm{~V}$ for the ice cloud region between 11 and $14 \mathrm{~km}$ suggesting particle overlap and multiple scattering which might have led to signal saturation. This portion of the profile is more vulnerable for the data correction which has been performed and shown in Fig. $3314 \mathrm{a}$. 


\subsubsection{Lidar data processing}

Though the backscattered data at very high altitudes $(>30 \mathrm{~km})$ are not significant, it is used as background signal for noise correction. Range corrected signal (RCS) from MPL/Mie is calculated from noise corrected backscattered signal multiplied with range square. In general, the RCS indicates the intensity of light backscattered from molecules, aerosols and clouds in the atmospheric column. However, inversion techniques are commonly applied to the RCS with an assumption of lidar ratio (the ratio of extinction coefficient to backscattering coefficient) to obtain the profiles of total backscatter coefficient, extinction coefficient of cloud/aerosol separately. Ground based lidar data were analyzed at their actual vertical resolutions. However, CALIPSO data were interpolated and processed at every $30 \mathrm{~m}$ resolution. This information is used in discussion ( $\sec 3.1)$.

\subsubsection{Estimation of saturation relative humidity}

Two dedicated radiosondes from iMet and Meisei were employed in the balloon campaigns for measurement of meteorological parameters (temperature, pressure, relative humidity, and horizontal winds, with respect to height) as well as to act as interface with specialized sondes COBALD and CPS, respectively. As mentioned, temperature and pressure profiles from the radiosonde were used in post-processing of COBALD sonde to scale the signal to the molecular Rayleigh scattering. In addition to this, radiosonde temperature, relative humidity is useful in understanding the state of saturation of water vapor in the column. By convention, relative humidity reported from radiosonde is always over the plane surface of liquid water (because radiosonde relative humidity sensors are factory calibrated) even below $0^{0} \mathrm{C}$. This is because water droplets may exist even below $0^{\circ} \mathrm{C}$ and down to -30 to $-40^{\circ} \mathrm{C}$ (in the form of super cooled liquid) in the atmosphere. Saturation relative humidity (SRH) defined in Fujiwara et al. (2016) (see also Fujiwara et al., 2003) as the ratio of saturation vapor pressure over the plane surface of ice $\left(e_{\mathrm{si}}\right)$ to water $\left(\mathrm{e}_{\mathrm{sl}}\right)$ expressed in units of percentage can be a good metric to describe the state of water vapor in the atmosphere such as sub-saturation, saturation and/or super-saturation in particular at air temperatures below $0^{\circ} \mathrm{C}$ (with respect to ice). In this study, both $\mathrm{e}_{\mathrm{sl}}$ and $\mathrm{e}_{\mathrm{si}}$ are calculated using Hyland and Wexler formulation (see Appendix A of Murphy and Koop, 2005) by using radiosonde temperature data. For the temperatures

355 warmer than $0^{\circ} \mathrm{C}$, water vapor saturation is indicated by $100 \% \mathrm{RH}$. For temperatures colder than $0^{\circ} \mathrm{C}$, water vapor is said to 356 be saturated if $\mathrm{RH} \sim=\mathrm{SRH}$ and super-saturated when $\mathrm{RH}>\mathrm{SRH}$. This information is used in discussion (sec 3.2). 


\subsubsection{Discrimination of cloud and aerosol in a balloon profile}

$$
\text { COBALD measurement always represents backscatter light from the combination of aerosol and cloud. Obtaining }
$$
information on aerosol (only) is not possible (for COBALD) in the presence of clouds, and the corresponding regions have to be identified and rejected. This cloud clearing has been established previously for studies related to the UTLS region (Vernier et al., 2015, 2018). Contrary, for cloud investigation, the COBALD was used in combination with the Cryogenic Frost point Hygrometer (CFH) to identify super saturation (with respect to ice) below, above and within the cirrus clouds to improve the understanding of microphysical processes in cirrus clouds (Cirisan et al., 2014). This sonde in addition detected volcanic aerosol tracers in the stratosphere (Vernier et al., 2020). The Asian Tropopause Aerosol Layer (ATAL) is a welldocumented phenomenon occurring in the UTLS region during the Summer Monsoon Season over South Asia. Vernier et al. (2015) proposed two cloud clearing methods for discrimination of aerosol from cirrus clouds in ATAL region using the physical quantities Color Index (CI), relative humidity over ice (RHi) and backscatter ratio (BSR) at 940 or $532 \mathrm{~nm}$ (the latter was interpolated from the $455 \mathrm{~nm}$ data for inter-comparison with CALIOP). In the presence of CFH data, the RHi cloud-filtering approach classifies ATAL/UTLS aerosol layers by the criterion BSR (at $532 \mathrm{~nm}$ ) $<1.3$ and RHi $<70 \%$. For measurements of COBALD alone, the CI method indicates clouds with CI $<7$ and BSR (at $940 \mathrm{~nm}$ ) $<2.5$. It was shown that both methods effectively discriminate ATAL aerosol from upper tropospheric thin clouds. Brunamonti et al. (2018) also applied the cloud clearing criteria (BSR at $940 \mathrm{~nm}<2.5$, CI $<7$ and RHi $<70 \%$ ) following Vernier et al. (2015) and found a clear signal of enhanced BSR (at $455 \mathrm{~nm}$ ) between 1.04 and 1.12 indicative of the aerosol population in the ATAL region. However, it is noted that the methods proposed by Vernier et al. (2015) and Brunamonti et al., (2018) were developed for the UTLS aerosol and their applicability to COBALD measurements of boundary layer and/or mid-tropospheric aerosol needs to be validated.

In the present study, we made use of a CPS sonde in tandem with COBALD. As already mentioned, CPS is sensitive to particles in the size range of $>2 \mu \mathrm{m}$ and hence detects clouds particles (both liquid droplets and ice crystals) and sometimes coarse mode aerosol particles (such as dust) of these sizes. Fujiwara et al. (2016) has demonstrated in detail the potential of a CPS sonde using balloon sounding carried out at mid-latitude (Japan) as well as tropical sites (Indonesia). Narendra Reddy et al. (2018) have used a CPS measurement from Gadanki to validate their method of retrieving cloud 

COBALD measurements, CPS sonde has added advantage to the methods using simultaneous RH data described by Vernier et al. (2015) and Brunamonti et al. (2018). This implies wherever the cloud present in a profile, CPS identifies it (along with its phase) and the corresponding COBALD particle backscatter data refers to the cloud. The rest of the particle signals in the COBALD profile should correspond to aerosol. However, it may correspond to the (thin) cloud also which might have been missed or undetected by a CPS. So identification of aerosol and cloud in an altitude profile is key measurement of this paper. The concept is illustrated in sec 3.2 .

\subsubsection{Estimation of Aerosol-cloud-interaction Index}

Balloon data from all campaigns can be pooled to explore the aerosol-cloud relationship. For this purpose, a simple scheme is developed to carry out the required computations. CPS profile data is looked for a cloud layer presence in the altitude regime of liquid or low-level clouds (below $5 \mathrm{~km}$ ). As already discussed, CPS also identifies particle of nonspherical nature. In order to separate cloud particles from non-spherical particles, the following conditions have been imposed on various CPS measured parameters. Cloud particle count should be $>10 \# / s$, cloud droplet number concentration $>10^{-3} \# / \mathrm{cc}$, DOP $>0.6$, relative humidity $>95 \%$ and temperature $>0 \mathrm{degC}$. As there is a chance of randomly distributed data points in the measurement column satisfying the above conditions, we considered only those points present continuously up to a thickness minimum of $100 \mathrm{~m}$ (with at least one point for every $40 \mathrm{~m}$ ). Further, COBALD data of blue backscatter from $100 \mathrm{~m}, 200 \mathrm{~m}, 300 \mathrm{~m}, 400 \mathrm{~m}$ and $500 \mathrm{~m}$ below cloud base has been picked up separately (for the same profile) as proxy of aerosol to check its influence on the cloud above. As already mentioned, post processed data of backscatter ratio from COBALD sonde represents contribution from both molecule and particle (cloud and/or aerosol). Hence, particle backscatter ratio is obtained by subtracting backscatter ratio from one. In order to avoid high values of particle (blue) backscatter ratio possibly originating from the interaction with high relative humidity usually expected near to cloud base (boundaries), we have adopted two methods. First, high values of particle (blue) backscatter below the cloud base are removed if beyond a threshold value of 3.15. The threshold is arrived using a box plot (figure not shown) drawn for all the particle backscatter data set (for sounding with clouds) from cloud base to $500 \mathrm{~m}$ below and found 3.15 corresponds to the upper whisker $(\mathrm{Q} 3+1.5 *(\mathrm{Q} 3-\mathrm{Q} 1))$. Further, the particle backscatter data is corrected for relative humidity in case a statistically significant 

example from the scheme is shown in Fig. 5 for the launch conducted on 01 November, 2018 that depicts cloud layers, blue particle back scatter ratio below cloud along with shaded black dots (representative of aerosol back scatter ratio). The scheme is applied to the balloon sounding and the results were discussed in sec 3.4. al., 2003, 2006. ACI is defined as slope of the linear fit between logarithm of cloud proxies such as cloud optical depth, cloud particle radius and cloud droplet number with logarithm of aerosol proxy. ACI in this study has been estimated using the equation (5).

$$
A C I=\frac{d \log N c}{\operatorname{dlog} B S R b}
$$

where cloud droplet number count $(\mathrm{Nc})$ is taken as cloud proxy whereas BSRb is the COBALD (blue) particle back scatter taken as aerosol proxy and interaction between both is indicated by index ACI. It is to be noted that cloud particle number concentration is used here to represent cloud property instead of droplet number concentration as the former is a direct measurement (of CPS). The slope of linear fit between natural logarithm of Nc and BSRb indicates the magnitude of aerosolcloud interaction (ACI) index which should be between 0 and 1 (Feingold et al., 2003). Note this condition (eq.5) is independent of liquid water path as it verifies/quantifies the aerosol activation process.

\subsubsection{Uncertainty in ACI estimation}

The uncertainty in ACI stems from both uncertainty in COBALD backscatter ratio and CPS cloud particle counts. The slope of curve (linear fit of data on log-log scale) can be written as a function of BSRb (blue back scatter ratio) and Nc (cloud particle count) as,

$$
A C I=f(B S R b, N c)=\frac{\log N c-C}{\log B S R b}
$$

where ' $\mathrm{C}$ ' is the intercept of the curve. Partial derivative of $f(B S R b, N c)$ with respect to BSRb and $\mathrm{Nc}$ indicates uncertainty in ACI with respect to uncertainty in individual parameters ( $\mathrm{Nc}$ and $\mathrm{BSRb})$. The combined uncertainty (UC) in ACI is given by the equation,

$$
U C=\sqrt{\left(\frac{\partial f(B S R b, N c)}{\partial B S R b}\right)^{2}(u B S R b)^{2}+\left(\frac{\partial f(B S R b, N c)}{\partial N C}\right)^{2}(u N c)^{2}}
$$


where $u B S R b$ and $u N c$ are individual uncertainties.

432

433

\section{Results}

The multi-instrument data from the BACIS campaigns are presented in this section. Consistency among multiple measurements is discussed in Section 3.1, data from a particular balloon sounding (campaign) are interpreted in detail in Section 3.2, statistics on cloud/aerosol features are given in Section 3.3, and finally, the relationship between aerosol and cloud is illustrated in Section 3.4.

\subsection{Consistency of balloon measurements}

The combination of COBALD and CPS sondes is used for the first time for in-situ measurement of aerosols and clouds. Therefore, it is important to know the performance of these sondes in comparison to other measurement techniques. Here, we make use of data from two pilot campaigns to demonstrate the consistency of balloon borne measurements with that of ground based and space borne remote-sensing instruments. As mentioned previously, the first two (pilot) campaigns have been conducted in line with the proposed concept.

\subsubsection{Pilot campaign-1 (launch held on 06 June 2017 at 01:50 LT)}

The CALIPSO satellite overpass time for the first pilot campaign was around 02:00 LT of 06 June 2017 (starting time of the track). The balloon was launched at 01:50 LT on the same day just before CALIPSO overpass time. Combined measurements from specialized balloon borne sondes, ground based and space borne lidars obtained during the first launch of the campaign are shown in Figure 6.

The BSR from COBALD sonde at $455 \mathrm{~nm}(950 \mathrm{~nm})$ is plotted in Fig. 6d as blue (red) line. BSR from both the channels are referenced to same $\mathrm{x}$-axis scale. Similarly, cloud particle number concentration (dN, \#/cc) from CPS sonde is plotted as black dots (Fig.6e). On the other hand, range corrected signal (RCS) from ground based lidars (Mie, MPL) is averaged over a short period of time during CALIPSO overpass and plotted in magenta (averaged from 01:50 to 02:00LT), orange color lines (averaged from 01:50 to 01:55 LT), respectively (Fig.6f). The total attenuated backscatter $\left(\mathrm{km}^{-1} \mathrm{sr}^{-1}\right)$ from CALIPSO is also averaged for the profiles found nearest to the location and shown in olive green color line (Fig.6f). The significant peaks in physical quantities being compared among the different measurements are representative of response 
from clouds and aerosols in the atmosphere. At this point of discussion, we have not distinguished their contributions. The

balloon drifts away from the launch location with time, therefore, it is also required to check the degree of co-location of measurements with the lidars. In order to facilitate this, a portion of nocturnal variation (representing the balloon launch duration) in range corrected signal from both Mie and MPL is shown in Fig. 6b and 6c, respectively. The CALIPSO overpass track consisting of 166 profiles is also plotted as a function of longitude (Fig. 6a). For the sake of easy identification of simultaneous lidar measurements, the balloon indices such as height and drift (radial distance from launch location) are over plotted as a function of time on contour maps as shown in black and red colored lines, respectively (Fig. $6 b$ and $6 c)$.

Balloon borne in-situ measurements from COBALD and CPS show significant peaks in the lower tropospheric (below $4 \mathrm{~km}$ ) and upper troposphere (between 13 and $17 \mathrm{~km}$ ) at same altitude regions. It can be seen from the Fig. 6d and 6c, there is a good resemblance among the in-situ and MPL measurements in the lower tropospheric (below $4 \mathrm{~km}$ ). This is because almost no change in the atmospheric conditions as the balloon took approximately 15 minutes to reach an altitude of $4 \mathrm{~km}$ with a radial distance of $5 \mathrm{~km}$ away from the launch location. Mie lidar information is not reliable for this altitude region (below $4 \mathrm{~km}$ ) as it is not in the overlapping region of the telescope viewing geometry and laser beam dispersion (see section 2). CALIPSO signal also looks to be dispersed and noisy for this altitude region. This could be due to the attenuation of the signal from top side layers as seen in Fig. 6a at longitude of $79.24^{\circ} \mathrm{E}$ (nearest profiles longitude).

Next to this is the sharp peak seen in COBALD red channel at slightly below $9 \mathrm{~km}$ (Fig. 6d). This again can be seen in Mie and MPL profiles also (Fig. 6b, 6c) but at $8.4 \mathrm{~km}$ (slightly below cloud detection height). However, it is to be noted that these profiles are averaged for a short duration of time during the CALIPSO overpass. In fact, there is another peak in the Mie lidar profiles at $\sim 7.2 \mathrm{~km}$, (Fig. 6b) which is not seen in COBALD. It is approximately 45 min (around 02:45 LT) from the time of launch when the balloon reached the altitude of $\sim 9 \mathrm{~km}$ and $5.8 \mathrm{~km}$ away before detecting a sharp peak. As there is no significant range corrected signal during this time and altitude in the ground based lidar data (Fig. $6 \mathrm{~b}$ and $6 \mathrm{c}$ ), the sharp layer detected by COBALD may be a localized cloud layer or a passing layer which might have ascended/descended. Exact attribution can be made with a detailed study but it is beyond the scope of the current analysis. 
weak horizontal winds and thus weak associated wind drifts as well. Thereafter, the balloon started drifting rapidly due to high wind speeds between 10 and $20 \mathrm{~m} / \mathrm{s}$. Both the in-situ measurements of COBALD and CPS show strong double peaks from $~ 13-15.5 \mathrm{~km}$ and 16-16.5 km (Fig. 6d, e). Profiles from Mie, MPL and CALIPSO also showed similar peaks except MPL for which the upper side peak is missing (Fig. 6f). It may be once again noted that, these profiles are averaged for a short duration of time during CALIPSO overpass and return signal from MPL at high altitudes $(\sim 16 \mathrm{~km})$ during the same time suffered severely due to the presence of a mid-tropospheric cloud layer (at $\sim 7 \mathrm{~km}$ ) as seen in Fig. $6 \mathrm{c}$. This is not the case for return signal from Mie Lidar as the power and energy of Mie laser is relatively high (Fig. 6b). However, strong double peak structures can be noticeable in the simultaneous observations of both ground based lidars (Mie and MPL) at similar heights during the time corresponding to the balloon altitude of $13 \mathrm{~km}$ (post 03:00 LT). Therefore, same upper tropospheric cloud layers detected in the ground, space borne and in-situ measurements suggest they are extended cloud layers. Dynamical aspects of south-west monsoon over sub-continent refers to the presence of Tropical Easterly Jet (TEJ) which is strong enough to swipe anvil clouds of meso-scale convective systems to thousands of kilo meters (Sathiyamoorthy et al., 2013).

\subsubsection{Pilot campaign -2 (launch held on 08 July 2017 at 01:35 LT)}

The starting time of the CALIPSO over pass track for the second pilot campaign was at 02:00 LT. The balloon was launched at 01:35 LT nearly 30 minutes before the starting time of CALIPSO overpass. Data from all the instruments are plotted in Figure 7, which is prepared same as Figure 6. MPL, Mie profiles were averaged from 01:50 to 02:00 LT (close to the CALIPSO overpass time over Gadanki).

The observations from COBALD and CPS are matching reasonably well (Fig. 7d, e) as significant peaks were found in the lower troposphere $(0-5 \mathrm{~km})$ and upper troposphere $(10-16 \mathrm{~km})$. The profiles from space borne and ground based lidars (Fig. 7f) also show a similar response as in-situ measurements (both in lower and upper troposphere) except that lidar measurements exhibit additional peaks in the mid-troposphere (between 5 and $10 \mathrm{~km}$ ). It is to be noted that profiles from lidar measurements are averaged over a short time period, as mentioned before. 
Fig. 7 a, b \&c respectively. Due to high wind speeds $(10-20 \mathrm{~m} / \mathrm{s})$ the balloon drifted about $5 \mathrm{~km}$ away from the launch site while crossing boundary layer height $(\sim 2 \mathrm{~km})$. The features found within the boundary layer as measured by in-situ instruments (Fig. 7d) are in agreement with that of MPL measurements (Fig. 7c) for the same altitude region. Note that, Mie lidar measurements are not reliable at these low altitudes and CALIPSO not yet started passing by the launch site. The balloon continued to drift away but with the reduced wind speeds of $10 \mathrm{~m} / \mathrm{s}$. At around 4.3 and $4.7 \mathrm{~km}(10 \mathrm{~km}$ away of launch site) balloon had detected two layers (strong peaks). The time corresponding to this balloon height was around 01:50 LT and at this point of time two layers can also be seen in both the ground based lidars at same altitudes (Fig. 7b and c) indicating the presence of an extended layer (which is evident in in-situ and ground based measurements). In fact, the layer at $4.7 \mathrm{~km}$ was also noticeable in the CALIPSO profile measurements (Fig. 7a). This is because the CALIPSO started coming close by site when the balloon was at this height and CALIPSO profile corresponding to average of (nearest) profiles at around $79.32^{0}$ E longitude (Fig. 7a). Further, the balloon started drifting towards the launch site until it reached a height of $\sim 7.5 \mathrm{~km}$ at a distance of $\sim 13 \mathrm{~km}$ away. While moving towards the site, the balloon started detecting the layers starting from $11 \mathrm{~km}$. The time corresponding to the balloon height of $11 \mathrm{~km}$ is around 02:45 LT and at this point of time simultaneous MPL data show almost weak returns (Fig. 7c), whereas Mie lidar show a better return signal (Fig. 7b) than MPL. In continuation to this, balloon started drifting further towards the site until it reached as close as $\sim 3.5 \mathrm{~km}$ at a height of $\sim 12.5$ $\mathrm{km}$. Thereafter, it started moving rapidly away from the location with high wind speeds due to the characteristic of TEJ. Multiple layers of clouds have been nicely captured by in-situ measurements from $11 \mathrm{~km}$ to $\sim 16 \mathrm{~km}$. However, prominent lidar returns were not noticeable in the simultaneous observations of Mie and MPL. This is because of a strong lower tropospheric cloud layer present at around $5 \mathrm{~km}$ limiting the detection of upper tropospheric cloud layers by both groundbased lidars. However, all these layers were prominently captured in CALIPSO observations as it is top down laser probing. In summary, the data from both the pilot campaigns illustrate the limitations of the ground based and/or space borne lidars in detecting the complete cloud vertical structure. At the same time, in-situ data emphasize the consistency of the balloon borne measurement with the ground based as well as space borne measurements and complements to the remote sensing technique while detecting the missing portion of the cloud vertical structure. 
A typical example of high-resolution vertical wind measurements obtained from MST Radar during 8 July 2017 is shown in Figure 8(f) and profiles of all the three-dimensional winds averaged between 02:30 LT to 03:30 LT are shown in Figures 8(a)-(c) to compare the wind measurements. We also superimpose the zonal and meridional winds in the respective panels obtained from radiosonde for comparison. Consistency in the measured winds in these two independent techniques can be noticed. Since this campaign falls in the Indian Summer Monsoon season, easterly wind velocities exceeding $50 \mathrm{~m} / \mathrm{s}$, which is called as TEJ, can be noticed between 14-16 km altitudes as a part of synoptic-scale systems (Fig. 8a). In addition, zonal winds are westerly, which is also part of a large-scale monsoon system. These winds play a crucial role in bringing clouds and aerosol from far away sources. In general, meridional winds are weaker and mostly southerly (Fig. 8b). Vertical winds show mostly updrafts, except in the UTLS region where downdrafts are noticed (Fig. 8c) and similar features persist through this campaign (Fig.8f). Occasional patches of updrafts and downdrafts can be noticed during the campaign, which is associated with monsoon convection. These vertical wind acts in upliftment of aerosol and clouds. Enhanced SNR layers are also noticed (Fig. 8d) at few altitudes mostly related to large temperature and water vapor gradients generally occur in the presence of clouds. Doppler width (Fig. 8e) shows higher values below the boundary layer and UTLS region suggesting active turbulence.

\subsection{Interpretation of aerosol and cloud features in a balloon profile}

In order to fulfill the primary objectives of the campaign, it is a priority to distinguish aerosol and cloud in a balloon borne in-situ profile. In connection with this, combined measurements of CPS and COBALD from a balloon sounding held on 27 June 2019 at 23:30 LT is interpreted as shown in Figure 9. This particular sounding is selected because it showcases all the features that can be detectable by a CPS sonde in a profile such as liquid cloud, super cooled liquid cloud, ice cloud, and non-spherical particle layers. INSAT3D brightness temperature shown in Figure S1 indicates the evolution of a localized cloud system north of the observational site initiated few hours before the launch and eventually spreading over the site. $(\mathrm{RH})$, temperature (T) obtained from RS-11G radiosonde are plotted in Fig. 9a (wine red and blue color lines). In the Fig.

$5529 \mathrm{a}, \mathrm{SRH}$ is also shown (in yellow color). The SRH and RH can be read from same top-X scale in wine red color as shown in 553 Fig. 9a. 

corresponding profiles of T, RH, and SRH. From Fig. 9d, DOP values close to 1 (from 0.6 to 1 ) are noticeable at different altitude ranges in the profile viz., 3.5 to $5.5 \mathrm{~km}, 8.6$ to $9 \mathrm{~km}$ and DOP values spread (-1 to 1) between 9 and $11 \mathrm{~km}$. In the altitude range from 3.5 to $5.5 \mathrm{~km}$, CPS detected multiple liquid cloud layers, corresponding to the multiple layers of $100 \%$ RH. However, the corresponding COBALD blue and red backscatter data points are limited (Fig. 9b). This is because COBALD backscattered signals showed missing values due to saturation of photo diodes in the presence of thick liquid cloud layers and that had to be removed during post-processing of data and are not discussed further. $8.7^{\circ} \mathrm{C}$, respectively, indicating saturation of water vapor with respect to liquid ( $\mathrm{RH} \sim=\mathrm{SRH}$ ) which is conducive for the formation of a (liquid) cloud. Further, majority of droplet number concentration in this liquid cloud layer range between 0.1 to $1 \# / \mathrm{cm}^{3}$. A rough estimate on particle size information (water droplet or ice crystal) can be inferred from CPS voltage data (I55). According to Fujiwara et al. (2016), I55 mostly lying below 1V suggests these droplets are sized $\sim 2-13 \mu$ m. Another liquid cloud layer extending from 4 to $4.4 \mathrm{~km}$ (400 m thick) is observed with vapor saturation over liquid (100\% $\mathrm{RH})$ and temperatures from $3-6^{0} \mathrm{C}$. CPS shows that droplet number concentration peaks in the range $0.1-10 \# / \mathrm{cm}^{3}$ with highest in 0.1 $1 \# / \mathrm{cm}^{3}$. The intensity (I55) values $(<1 \mathrm{~V}$ ) indicate majority of droplet sizes are $\sim 2-13 \mu \mathrm{m}$. The third liquid layer in the range 3.5 to $5.5 \mathrm{~km}$ is observed between $5.1-5.5 \mathrm{~km}$ (400 m thick) with highest droplet number concentrations in the range 0.1-10 $\# / \mathrm{cm}^{3}$, sized around 2-13 $\mu \mathrm{m}(\mathrm{I} 55<1 \mathrm{~V})$. However, RH observations show $100 \%$ RH or RH $>$ SRH ie. water vapor supersaturated over ice at temperatures slightly below $0^{0} \mathrm{C}\left(0\right.$ to $\left.-3^{0} \mathrm{C}\right)$, suggesting that the cloud layer may be composed of super cooled liquid droplets. Another clear super cooled cloud layer was detected between 8.6 and $9 \mathrm{~km}$ (400 m thick) with supersaturation of vapor over ice at $100 \% \mathrm{RH}$ or $\mathrm{RH}>\mathrm{SRH}$ and -21.5 to $-23.5^{\circ} \mathrm{C}$ temperatures. The observed features of droplet number concentration and particle size are similar to those for the super cooled cloud found in the lower atmosphere. The only difference that could be noticeable is in the distribution of DOP values as shown in Figure S2, which indicate the more tendency of droplets towards non-sphericity in the mid-tropospheric super cooled liquid cloud. COBALD signals found 
The top-most layer in the upper troposphere spreading from $9.5-11 \mathrm{~km}$ is an ice cloud layer as per its DOP values.

The temperatures within the cloud are found in the range -22 to $-40^{\circ} \mathrm{C}$. RH values are $>\mathrm{SRH}$, suggesting the super-saturation of vapor (over ice) within the ice cloud. Histogram of data for all the parameters obtained from COBALD and CPS for this ice cloud layer $(9-11 \mathrm{~km})$ is shown in Figure 10. The number concentration of ice cloud particles (Fig. 10a) lies between 0.01 to $10 \# / \mathrm{cm}^{3}$ with a peak in the range $0.1-1 \# / \mathrm{cm}^{3}$. Non-sphericity of particles is clearly seen by the wide distribution of DOP values in the range -0.4 to 1 with majority of them lying close to 0 (Fig. 10b). In particular, DOP values close to 0 indicate (see section. 2) both plane and cross-polarization intensities of scattered light (I55 and I125) are comparable. This happens when both detectors get saturated due to large number of small size particles and/or few large sized ice particles or both. In support of this, the I55 values (Fig. 10c) are found peak in the 7-8 V range ( 7.5 V) for such cases. Further, if saturation voltages are due to large size then they may correspond to $\sim 80-140 \mu \mathrm{m}$ or greater ice particles (corresponding to I55 of $\sim 7.5 \mathrm{~V}$ ), assuming that the results from laboratory experiments by Fujiwara et al. (2016) using standard spherical particles can be applied for these ice clouds. Apart from this, a second peak in 155 noticed below 1V corresponds to ice particles roughly sized between 2 and $14 \mu \mathrm{m}$.

The COBALD BSR corresponding to this ice cloud are symmetrically distributed from 1-10 and 10-100 for blue (Fig. 10d), red (Fig. 10e) wavelengths, respectively. However, there are some observations which are beyond 10(100) at blue (red) wavelengths. Similarly, the CI for this cloud (Fig. 10f) is found mostly between 10 and 20 but for few instances, it is observed from 20 to 40. From the definition (see section 2), the CI is independent of the number concentration hence it can be used as an indicator of mode radius of particles. With the assumption of a single mode log-normal size distribution of spherical aerosol/cloud particles, Mie calculations show CI is 4-10 for small particles of mode radius up to 1-2 $\mu$ m and 14-20 for large particles of $2-20 \mu \mathrm{m}$. CI converges to around 20 as a geometric limit for very large particles of mode radius $>\sim 50$ $\mu \mathrm{m}$. However, CI can have values $>20$ at mode radius $2-20 \mu \mathrm{m}$ as $\mathrm{CI}$ is a non-monotonous function of mode radius and exhibits Mie oscillations (due to variations of scattering efficiencies with size parameter). The amplitude and frequencies of Mie oscillations depend on the width of the log-normal size distribution assumed. At width higher than say 2 (represent poly disperse aerosol populations) these oscillations are mitigated and lead to monotonous dependency of CI and mode radius. For stratospheric aerosols in the size range 0.02-0.4 $\mu \mathrm{m}$ the $\mathrm{CI}$ is found to be in the range 5-7 (Rosen and Kjome, 1991). This 
603 is because stratospheric aerosols exhibit size distributions with narrow standard deviations. Aerosol size distributions in the

604 UTLS region may also be assumed as log-normal (similar to stratospheric aerosols) hence the criteria CI $<7$ might have

605

606

607

608

609

610

611 suited for cloud filtering in ATAL region (see Section 2). For the present case of ice cloud layer (9-11km) discussed above, CPS indicates presence of small $(2-14 \mu \mathrm{m})$ and very large ice particles $(>80 \mu \mathrm{m})$. So, the standard deviation of log-normal size distribution in the cloud layer of large particle mode must be wider. Therefore, Mie oscillations may be expected to be minimum. Probably because of this, majority of CI values for the cloud layer are found between 15 and 20, which may correspond to mode radius of $>\sim 50 \mu \mathrm{m}$ (geometric limit). It may also be concluded that the CI of 20-40 (with very few values $>30$ ) corresponds to small particles of mode radius $>2-20 \mu \mathrm{m}$ (due to Mie oscillations). COBALD size interpretations (based on CI) are in support of CPS based size interpretations. Since the majority of CI falls between 15 and 20, the I55 of $\sim 7.5 \mathrm{~V}$ in CPS would have been caused by large size particles.

In the lower troposphere up to $2 \mathrm{~km}$ where water vapor is well sub saturated (50-70\% RH), CPS also shows particle signals (Fig. 9c). The DOP values range from -0.4 to 1 but with lower number concentrations $\left(0.001-0.01 \# / \mathrm{cm}^{3}\right)$ and less than $1 \mathrm{~V}$ of backscatter intensity (I55), indicating these particles as non-spherical in shape similar to the ice cloud particles. Since it is not possible to have ice cloud particles at these lower altitudes in dry conditions ( $\mathrm{RH}<70 \%)$, it may be possible that these particles are coarse mode non-spherical aerosol particles. COBALD observations indicate CI of 11-12. Thus, both the COBALD and CPS observations indicate aerosol may be of size $\sim 2-5 \mu \mathrm{m}$. To investigate the possible origin of these coarse mode aerosol particles, Hysplit 7-day back trajectories for 5 days before and after the date of launch are calculated and shown in Figure S3 (in different color lines). These Hysplit back trajectories (Stein et al., 2015) indicate the air parcel path ways ending at every $1 \mathrm{~km}$ altitude from 1 to $5 \mathrm{~km}$ over Gadanki at the time of balloon launch (18 UTC). It can be seen (from Fig. S3) that, the air masses were originated from the Indian Ocean passing through the Arabian Sea before reaching the Gadanki location for heights 1 to $3 \mathrm{~km}$. Therefore, the air masses were of marine origin, and the particles were possibly coarse mode water soluble particle (such as sea salt) which can grow hygroscopic due to the availability of moisture over the Ocean surface (Mishra et al., 2010; Ratnam et al., 2018). The rain water chemical analysis reported by Jain et al. (2019) at Gadanki supports this conclusion as they found dominance of water soluble ions during the southwest monsoon (June to September). Above $3 \mathrm{~km}$ altitude, the air masses are coming from the Saharan desert region within 7 days which may bring 
non-spherical coarse mode dust particles to the launch location (Mishra et al., 2010). Thus, in case of lower tropospheric coarse mode aerosol (water soluble aerosol particles), the CI can be $>7$ at $\mathrm{RH}<70 \%$.

In the altitudes of 6-8.5 km (Fig. 9), CPS has detected no cloud. However, COBALD data shows, CI values ranging from 3-8 in the altitude range 6-7 $\mathrm{km}$ and 3-12 in the range 7-8.5 $\mathrm{km}$ may indicate presence of aerosol particles undetectable by CPS (i.e., of sizes $<2 \mu \mathrm{m}$ ). RH values indicate sub saturated conditions throughout this altitude region. However, between $7 \mathrm{~km}$ and $8.5 \mathrm{~km}, \mathrm{RH}$ increases and becomes greater than the ice saturation RH values (saturation with ice). Corresponding to this RH change, CI as well as red channel BSR is also found to increase. This suggests the growth of small aerosol particles under high humidity conditions until the RH approaches ice saturation where super cooled liquid droplets are observed (8.6-9 km) in CPS whose features have been discussed already. Since the COBALD CI values are mostly $<10$ in this altitude range, the majority of particles detected might be sized up to $1-2 \mu \mathrm{m}$.

\subsection{Statistics on COBALD color index}

In order to generalize the optical properties specific to aerosol and cloud, combined data from COBALD and CPS (from multiple launches) has been investigated in detail. The liquid/super cooled cloud, ice cloud and non-spherical particle layer depth are carefully identified with the help of DOP data from CPS (discussed in Section 2). The corresponding data of temperature, relative humidity, BSR, CI, and peak particle number concentration have been picked up for estimating statistics. Further, threshold values of COBALD parameters were tried to identify for the said categories of aerosol and cloud cases. Among 15 balloon soundings, those soundings were considered where CPS detected cloud particles and both blue and red channel data are not missing from COBALD. With these conditions, 8 balloon soundings were identified for estimating statistics.

Table 3 shows the mean (median) values of $\mathrm{CI}$ and other parameters corresponding to the ice cloud layers from 7 launches. Fig. 11(a) shows the complete statistics of CI in the form of a box plot for same ice clouds layers. Fig. 11(b) shows histogram of CI from each campaign indicated by different colors. From Table 3, ice clouds are seen above $9 \mathrm{~km}$ with temperatures colder than $-20^{\circ} \mathrm{C}$. For example, an ice cloud layer was found between 9.3 to $16 \mathrm{~km}$ on 30 April 2019 with temperatures in the range -22 to $-79^{\circ} \mathrm{C}$, RH close to $\mathrm{SRH}$ and mean (median) value of $\mathrm{CI}$ is 19.4 (19.3), BSR is 16.4 (8.6) at $455 \mathrm{~nm}, 302(147)$ at $940 \mathrm{~nm}$, peak droplet concentration is in the range $10^{-1}$ to $1 \# / \mathrm{cc}$. Similarly, from Table 3, the range of 

respectively. Therefore, it is difficult to arrive at threshold values of BSR for ice clouds based on Table 3. This may be partly due to the fact that BSR depends not only on the particle number concentration but also the size. However, it is interesting to note (except few cases in Table 3) that BSR data of ice clouds (at both channels) tend to be greater for densely populated clouds. On the other hand, difference between mean and median values of CI is not large, thus not much variance in CI within the ice cloud. It is also clear from Table 3 and Fig. 11(a) that about 90-95 percentile of CI values of ice cloud are above 15 and below 25 with mean/median values in the range 18-20. The same is also seen in the histogram of CI shown (Fig. 11b) in different colors for different sounding dates where a greater number of points in a sounding are lying close to 20. Therefore, it may be concluded that the mean value of CI of ice clouds would be between 18 and 20 . that liquid clouds were not observed as often as ice cloud in the balloon data. In the second campaign (8 July 2017) a liquid cloud layer was observed at altitude from 4.7 to $4.86 \mathrm{~km}(160 \mathrm{~m})$ with $\mathrm{RH}>\mathrm{SRH}$, temperatures in the range -0.4 to $-1.65^{\circ} \mathrm{C}$. The mean value of CI corresponding to this liquid cloud layer is very high around 50. Similarly, another liquid cloud layer was observed in the fourth campaign (01 Nov. 2018) in the altitude range of 2-2.3 km (300 m). The corresponding CI values are high and above 100 (up to 200). Couple of thin super cooled liquid cloud layers were also identified on the same sounding between 6.1-6.17 $(7 \mathrm{~m})$ and 6.6-6.8 $\mathrm{km}(200 \mathrm{~m})$. The corresponding CI values are found with mean (median) values of 19.5 (19.4) and 32.6 (32.8), respectively. Apart from this, a strong boundary layer (liquid) cloud layer was observed on 23 Mar. 2019 (fifth campaign) between 0.9 and $1.2 \mathrm{~km}(300 \mathrm{~m})$. The corresponding CI of liquid cloud was found to be high with mean, median values of 60-80. From the above discussion (including the liquid cloud cases not discussed above), it is noticed that the CI for liquid clouds is high. The difference in CI values of liquid clouds can be attributed to the thickness of cloud, density and droplet size of liquid clouds.

RH is far less than $100 \%$. Statistics on COBLAD CI (and other parameters) for these non-spherical particle cases are presented in Table 4 using the data from 8 soundings. For example, a non-spherical particle layer was found between 0.5 and $6772.5 \mathrm{~km}$ altitudes on 06 June 2017 with temperatures in the range 15.5 to $27.6^{\circ} \mathrm{C}$ and relative humidity is dry from 63.5 to 

$455 \mathrm{~nm}, 6.5(6)$ at $940 \mathrm{~nm}$ and peak particle concentration is between $10^{-3}$ and $10^{-1} \mathrm{\#} / \mathrm{cm}^{3}$. The peak particle concentration of all non-spherical layers is found to be in the same range and hence not shown. From Table 4, it can be noticed that the nonspherical particle (aerosol) layer is found from near surface to the $5 \mathrm{~km}$ altitude depending on the month or season. During the monsoon season (font in blue color in Table 4), non-spherical particle layers were observed mostly from near surface $(500 \mathrm{~m})$ to $2.5 \mathrm{~km}$ whereas during pre-monsoon (font in wine red color) it is found from 0.5 up to $5 \mathrm{~km}$. The reason for difference in layer thickness among seasons may be attributed to the mixing within lower troposphere, long-range transport and local sources. Since these layers are confined mostly to the lower troposphere, the temperatures are in the range 27 to below $0^{0} \mathrm{C}$. From the above statistics (pre-monsoon and monsoon cases) it may be stated that the mean/median value of CI for the non-spherical particle layer is distributed between 11 and 15, irrespective of environmental humidity and season. BSR values for non-spherical layer are between 1.4 and 3.5 at $455 \mathrm{~nm}$, whereas little spread in red channel.

\section{9}

690

691

692

\subsection{Illustration of aerosol-cloud relationship}

In this section, an attempt is made to demonstrate the method to identify the relationship, if any, between aerosol and cloud properties observed using balloon observations of the BACIS campaigns. In the present analysis we have restricted ourselves to only liquid or low-level clouds as aerosol interactions in these cloud categories are well established (Bruce A. Albrecht, 1989; Twomey, 1977).

The scheme (discussed in sec. 2) is applied to the 15 balloon soundings of the BACIS campaigns and 6 launches have been observed with low-level cloud and aerosol layers. Further, a scatter plot between logarithm values of the median cloud particle count of cloud layer and logarithm of median values of aerosol (blue) back scatter below cloud base (for 300, 400 and 500m) is plotted in Fig. 12. A linear fit (line) of log-log values is also shown separately for all depths. It is noticed for depths 100 and 200m below cloud base relationship between aerosol, cloud cannot be discussed due to lack of data points of aerosol backscatter ratio from individual campaigns. This could be the result of elimination of high value of COBALD particle back scatter (>3.15) observed in this region (100 and 200m below cloud base). In the cloud boundaries of about 100 and $200 \mathrm{~m}$ below cloud base, intermediate region exists where aerosol transformation to cloud particle/growth takes place.

Hence it is tricky to have aerosol observation in this region. On the other hand, with similar elimination criteria (Section 2), 

good positive relationship is found between aerosol backscatter and cloud particle count with a statistically significant Pearson correlation coefficient of about 0.9 and slope (ACI index) of 0.77 and 0.86 when aerosol is considered from 300 and $400 \mathrm{~m}$ below cloud base, respectively. For depth of 500m from cloud base, the slope has decreased to 0.67 (correlation coefficient is also not significant with p-value $>0.05$ ) indicates aerosol influence weakens if region below $400 \mathrm{~m}$ from cloud base is considered. Therefore, it may be better to consider aerosol up to a depth of $400 \mathrm{~m}$ (below the cloud base) for understanding their influence on cloud properties. It is also emphasized that the slope (ACI index) value obtained in this analysis at all depths are well within the theoretical range of 0 to 1 . However, with a greater number of balloon soundings it might be possible to have statistically significant aerosol data after constraining the similar background/meteorological conditions to delineate their possible effects. Sounding from (with a low-level cloud layer) 04 February 2020 is ignored due to high values of COBALD return signal possibly due to an optical interference. The individual uncertainties in BSRb and $714 \mathrm{Nc}$ were assumed to be 5\% and the combined uncertainty in ACI index is estimated as discussed in Sec. 2.4.7 (equation.7). It 715 is found that the combined uncertainty in estimated ACI index is found from 0.01 to 0.23 and 0.08 to 0.13 , respectively for particle backscatter data from 300 and $400 \mathrm{~m}$ below cloud base.

\section{4. Summary}

The BACIS (Balloon borne Aerosol Cloud Interaction Studies) field campaigns have been conceptualized and successfully conducted using multiple-instruments from Gadanki $\left(13.45^{0} \mathrm{~N} ; 79.2^{0} \mathrm{E}\right)$, a location in Southern peninsular India. Meteorological balloon payload with a combination of lightweight and specialized sondes such as COBALD and CPS have been launched for the first time prior to a CALIPSO satellite overpass (close by Gadanki). Ground-based Lidars (MPL/Ceilometer/Mie lidar), Radars (MST Radar/LAWP) were also operated during the campaign period. So far 15 balloon soundings have been conducted as part of the BACIS campaigns.

During first two (pilot) campaigns all essential ground based and space borne instruments were available. Consistency in balloon borne in-situ measurements (CPS and COBALD) is assessed using the data from ground/space borne remote sensing instruments (CALIPSO, MPL and a Mie lidar) from two pilot campaigns (early hours of 6 June and 8 July 
and in-situ measurements. It is observed that the in-situ balloon soundings using combination of specialized (COBALD and CPS) sondes adds to the cloud and aerosol information than can be obtained from an individual ground/space borne instrument.

In order to discriminate aerosol from clouds in a profile, combined observations of COBALD and CPS from a campaign held on 27 June 2019 were inferred in detail. Using CPS data, liquid, super cooled, ice clouds were identified. COBALD data of BSR corresponding to the ice clouds was found to be 1-10 (at blue channel) and CI of 10 to 20. In addition to cloud features, CPS has also detected cloud particle layers at low altitudes (under dry conditions). These layers may be regarded as non-spherical (coarse mode) aerosol particle layers as ice clouds (with non-spherical cloud particles) cannot exist at lower heights. An attempt is also made to infer the size of cloud particle using the CPS data of intensity of scattered light (I55) and the COBALD color index. Based on CPS scattered light, the liquid droplet size (for the above case) is estimated to be 2-14 $\mu \mathrm{m}$, and for ice particles it is combination of particles with $80-140 \mu \mathrm{m}$ and 2-14 $\mu \mathrm{m}$. The estimates of ice particle sizes using CI data from COBALD supported the size interpretations of ice particles by CPS.

Further, combined observations from COBALD and CPS (BSR, CI, and peak particle number concentration data based on information on the cloud phase) are analyzed from multiple (eight) balloon soundings from BACIS Campaigns. From these statistics, it is found that the mean value of CI of ice cloud is found between 18 and 20. BSR (at both wavelengths) have a wide range of values hence threshold values for ice clouds could not be arrived. However, in some cases, we noticed, BSR increased with ice clouds of more droplet number concentration. In the case of non-spherical particle (aerosol) layers (in the lower troposphere), the mean values of CI and BSR (at $455 \mathrm{~nm}$ ) are found to be between 11 to 15 and 1.4 to 3.5, respectively. These non-spherical particle layers may correspond to coarse mode (dust) aerosols as discussed.

The relationship between aerosol and cloud in low-level (liquid) cloud is illustrated using balloon data from BACIS campaigns. CPS cloud particle count and COBALD particle backscatter at blue channel were considered as cloud and aerosol proxies, respectively. A scheme is developed to carefully identify the cloud layers from CPS data and particle (aerosol) backscatter below the cloud from COBALD data (in a profile). However, the relationships were analyzed separately using particle backscatter data from 100 to $500 \mathrm{~m}$ below the base height for first cloud layer. The results show, statistically significant correlation of 0.9 and slope (Aerosol-Cloud Interaction index, ACI) of 0.7 (0.86) obtained between 

uncertainty in the estimated value of ACI index is 0.01 to 0.23 and 0.08 to 0.13 , respectively for back scatter data from 300 and $400 \mathrm{~m}$ below the cloud base.

Statistical estimates/threshold value of CI, BSR for cloud (liquid/super-cooled/ice) and non-spherical particles attempted here will greatly help to separate a COBALD profile with respect to aerosol and cloud. However, immediate efforts are needed to understand the portion of COBALD profile with no cloud detection from CPS. This portion of COBALD profile may correspond to either aerosol with fine mode particles and/or a thin cloud not detectable by a CPS. On the other hand, estimates of size discussed here (from CPS, COBALD) are purely based on Mie theory and laboratory data. However, with assumptions of log-normal distribution of particles and measurements from COBALD (BSR, CI), theoretical estimate of particle size distribution of aerosol/cloud is possible. It makes sense to cross-check rough estimates of size from a CPS with COBALD size distributions rather than using CI variations. It is also planned to add a size distribution measurement to the balloon payload for cross verification and validation. Apart from this, in some of the cases, we have noticed COBALD return signal saturated for liquid/super cooled cloud in the presence of thick liquid cloud. Hence the information from a greater number of future launches will help to conclude the statistical figures/threshold values for liquid clouds as well as other cases of clouds, to discriminate the aerosol/cloud in a profile and to better quantify aerosol-cloud relationship. Further to this, attempts will be made to quantify aerosol-cloud interactions (with the multi-instrument data), particularly the role of vertical wind and turbulence on the aerosol-cloud interactions, ice cloud interactions, among others. In a nutshell, the results presented in the study indeed demonstrate the potential of observational approach/method, paves the way for future campaigns to understand aerosol-cloud process.

\section{Code/Data Availability}

Data analyzed in the study is made available on Zenodo (10.5281/zenodo.5749293). Data will also be shared with the interested users upon request and under collaboration.

\section{Author Contribution}


RKV is responsible for Conceptualization, Conducting experiment, Formal analysis, Visualization, Investigation,

Writing-original draft preparation; VRM is responsible for Supervision, helped in Visualization, Writing-review and editing. FM, HR and FGW are responsible for Writing-review and editing; MBL, RRM, RN helped in Visualization, Writing-review and editing; RN, ARST, HKA, RBS helped in conducting experiment, Writing-review and editing;

\section{Competing interest}

The authors declare that they have no conflict of interest.

\section{Acknowledgements}

Authors would like to thank the Director, NARL for supporting to conduct the field campaigns from NARL, Gadanki. Special thanks to the RADG and ASDG group members of NARL for their co-operation in the operation of Indian MST Radar, LAWP and Mie Lidar, respectively, during the launch period. We also would like express our thanks to the staff members of ARTG, balloon launch facility of NARL for extending their kind support for smoothly conducting balloon launches and recovery. CALIPSO science team is credited for providing the CALIOP data analysed in the study freely available at their webpage (https://www.calipso.larc.nasa.gov). We are also thankful to the Hysplit team for facilitating to run the HYSPLIT model on their server to simulate the air parcel back trajectories as per the requirement.

\section{References}

Abbott, T. H. and Cronin, T. W.: Through Increases in Humidity, Science (80-. )., 85(January), 83-85, 2021.

Brabec, M., Wienhold, F. G., Wüest, M., Krieger, U. and Peter, T.: A novel radiosonde payload to study upper tropospheric / lower stratospheric aerosol and clouds, 2008.

Brabec, M., Wienhold, F. G., Luo, B. P., VÃmel, H., Immler, F., Steiner, P., Hausammann, E., Weers, U. and Peter, T.: Particle backscatter and relative humidity measured across cirrus clouds and comparison with microphysical cirrus modelling, Atmos. Chem. Phys., 12(19), 9135-9148, doi:10.5194/acp-12-9135-2012, 2012.

BRUCE A. ALBRECHT: Aerosols, Cloud Microphysics, and Fractional Cloudiness, Science (80-. )., 245(4247), 24-29, 1989.

Brunamonti, S., Jorge, T., Oelsner, P., Hanumanthu, S., Singh, B. B., Ravi Kumar, K., Sonbawne, S., Meier, S., Singh, D., Wienhold, F. G., Ping Luo, B., Boettcher, M., Poltera, Y., Jauhiainen, H., Kayastha, R., Karmacharya, J., DIrksen, R., Naja, M., Rex, M., Fadnavis, S. and Peter, T.: Balloon-borne measurements of temperature, water vapor, ozone and aerosol backscatter on the southern slopes of the Himalayas during StratoClim 2016-2017, Atmos. Chem. Phys., 18(21), 1593715957, doi:10.5194/acp-18-15937-2018, 2018.

Brunamonti, S., Martucci, G., Romanens, G., Poltera, Y., Wienhold, F., Haefele, A. and Navas-Guzmán, F.: Validation of aerosol backscatter profiles from Raman lidar and ceilometer using balloon-borne measurements, Atmos. Chem. Phys. 
https://doi.org/10.5194/amt-2021-410

Preprint. Discussion started: 22 December 2021

(c) Author(s) 2021. CC BY 4.0 License.
Atmospheric

Measurement

Techniques

Discussions
808

809

810

811

812

813

814

815

816

817

818

819

820

821

822

823

Discuss., (May), 1-31, doi:10.5194/acp-2020-294, 2020.

Cherian, T., Kumar, Y. B., Reddy, B. S., Optics, G., Limited, A., Nr, R. S. and Road, N.: LIDAR for Atmospheric Measurement and Probing, , 5(84), 5114-5124, 2014.

Cirisan, A., Luo, B. P., Engel, I., Wienhold, F. G., Sprenger, M., Krieger, U. K., Weers, U., Romanens, G., Levrat, G., Jeannet, P., Ruffieux, D., Philipona, R., Calpini, B., Spichtinger, P. and Peter, T.: Balloon-borne match measurements of midlatitude cirrus clouds, Atmos. Chem. Phys., 14(14), 7341-7365, doi:10.5194/acp-14-7341-2014, 2014.

COAKLEY, J. A., BERNSTEIN, R. L. and DURKEE, P. A.: Effect of Ship-Stack Effluents on Cloud Reflectivity, Science (80-. )., 237(4818), 1020 LP - 1022, doi:10.1126/science.237.4818.1020, 1987.

Corrigan, C. E., Roberts, G. C., Ramana, M. V., Kim, D. and Ramanathan, V.: Capturing vertical profiles of aerosols and black carbon over the Indian Ocean using autonomous unmanned aerial vehicles, Atmos. Chem. Phys., 8(3), 737-747, doi:10.5194/acp-8-737-2008, 2008.

Costantino, L. and Bréon, F. M.: Analysis of aerosol-cloud interaction from multi-sensor satellite observations, Geophys. Res. Lett., 37(11), 1-5, doi:10.1029/2009GL041828, 2010.

Fan, J., Wang, Y., Rosenfeld, D. and Liu, X.: Review of aerosol-cloud interactions: Mechanisms, significance, and challenges, J. Atmos. Sci., 73(11), 4221-4252, doi:10.1175/JAS-D-16-0037.1, 2016.

Fan, J., Rosenfeld, D., Zhang, Y., Giangrande, S. E., Li, Z., Machado, L. A. T., Martin, S. T., Yang, Y., Wang, J., Artaxo, P., Barbosa, H. M. J., Braga, R. C., Comstock, J. M., Feng, Z., Gao, W., Gomes, H. B., Mei, F., Pöhlker, C., Pöhlker, M. L., Pöschl, U. and de Souza, R. A. F.: Substantial convection and precipitation enhancements by ultrafine aerosol particles, Science (80-. )., 359(6374), 411-418, doi:10.1126/science.aan8461, 2018.

Feingold, G., Eberhard, W. L., Veron, D. E. and Previdi, M.: First measurements of the Twomey indirect effect using ground-based remote sensors, Geophys. Res. Lett., 30(6), 19-22, doi:10.1029/2002GL016633, 2003.

Feingold, G., Furrer, R., Pilewskie, P., Remer, L. A., Min, Q. and Jonsson, H.: Aerosol indirect effect studies at Southern Great Plains during the May 2003 Intensive Operations Period, J. Geophys. Res. Atmos., 111(5), 1-13, doi:10.1029/2004JD005648, 2006.

Fujiwara, M., Shiotani, M., Hasebe, F., Vömel, H., Oltmans, S. J., Ruppert, P. W., Horinouchi, T. and Tsuda, T.: Performance of the Meteolabor "Snow White" chilled-mirror hygrometer in the tropical troposphere: Comparisons with the Vaisala RS80 A/H-Humicap sensors, J. Atmos. Ocean. Technol., 20(11), 1534-1542, doi:10.1175/15200426(2003)020<1534:POTMSW>2.0.CO;2, 2003.

Fujiwara, M., Sugidachi, T., Arai, T., Shimizu, K., Hayashi, M., Noma, Y., Kawagita, H., Sagara, K., Nakagawa, T., Okumura, S., Inai, Y., Shibata, T., Iwasaki, S. and Shimizu, A.: Development of a cloud particle sensor for radiosonde sounding, Atmos. Meas. Tech., 9(12), 5911-5931, doi:10.5194/amt-9-5911-2016, 2016.

Grosvenor, D. P., Sourdeval, O., Zuidema, P., Ackerman, A., Alexandrov, M. D., Bennartz, R., Boers, R., Cairns, B., Chiu, J. C., Christensen, M., Deneke, H., Diamond, M., Feingold, G., Fridlind, A., Hünerbein, A., Knist, C., Kollias, P., Marshak, A., McCoy, D., Merk, D., Painemal, D., Rausch, J., Rosenfeld, D., Russchenberg, H., Seifert, P., Sinclair, K., Stier, P., 
van Diedenhoven, B., Wendisch, M., Werner, F., Wood, R., Zhang, Z. and Quaas, J.: Remote Sensing of Droplet Number Concentration in Warm Clouds: A Review of the Current State of Knowledge and Perspectives, Rev. Geophys., 56(2), 409453, doi:10.1029/2017RG000593, 2018.

Gupta, G., Ratnam, M. V., Madhavan, B. L., Prasad, P. and Narayanamurthy, C. S.: Vertical and spatial distribution of elevated aerosol layers obtained using long-term ground-based and space-borne lidar observations, Atmos. Environ., 246(December 2020), 118172, doi:10.1016/j.atmosenv.2020.118172, 2021.

Haywood, J. and Boucher, O.: Estimates of the direct and indirect radiative forcing due to tropospheric aerosols: A review, Rev. Geophys., 38(4), 513-543, doi:10.1029/1999RG000078, 2000.

IPCC: Climate Change 2013: [online] Available from: https://www.ipcc.ch/pdf/assessmentreport/ar5/wg1/WGIAR5_SPM_brochure_en.pdf, 2013.

Jain, C. D., Madhavan, B. L. and Ratnam, M. V.: Source apportionment of rainwater chemical composition to investigate the transport of lower atmospheric pollutants to the UTLS region, Environ. Pollut., 248, 166-174, doi:10.1016/j.envpol.2019.02.007, 2019.

Jose, S., Nair, V. S. and Babu, S. S.: Anthropogenic emissions from South Asia reverses the aerosol indirect effect over the northern Indian Ocean, Sci. Rep., 10(1), 1-8, doi:10.1038/s41598-020-74897-x, 2020.

Kobayashi, E., Hoshino, S., Iwabuchi, M., Sugidachi, T., Shimizu, K. and Fujiwara, M.: Comparison of the GRUAN data products for Meisei RS-11G and Vaisala RS92-SGP radiosondes at Tateno (36.06 N, $\left.140.13^{\circ} \mathrm{E}\right)$, Japan, Atmos. Meas. Tech., 12(6), 3039-3065, doi:10.5194/amt-12-3039-2019, 2019.

Koren, I., Remer, L. A., Altaratz, O., Martins, J. V. and Davidi, A.: Aerosol-induced changes of convective cloud anvils produce strong climate warming, Atmos. Chem. Phys., 10(10), 5001-5010, doi:10.5194/acp-10-5001-2010, 2010.

Kulkarni, J. R., Maheskumar, R. S., Morwal, S. B., Padma Kumari, B., Konwar, M., Deshpande, C. G., Joshi, R. R., Bhalwankar, R. V., Pandithurai, G., Safai, P. D., Narkhedkar, S. G., Dani, K. K., Nath, A., Nair, S., Sapre, V. V., Puranik, P. V., Kandalgaonkar, S. S., Mujumdar, V. R., Khaladkar, R. M., Vijayakumar, R., Prabha, T. V. and Goswami, B. N.: The cloud aerosol interaction and precipitation enhancement experiment (CAIPEEX): Overview and preliminary results, Curr. Sci., 102(3), 413-425, 2012.

L'Ecuyer, T. S.: Touring the atmosphere aboard the A-Train (vol 63, pg 36, 2010), Phys. Today, 64(8), 10, 2011.

Lohmann, U.: Aerosol effects on clouds and climate, Space Sci. Rev., 125(1-4), 129-137, doi:10.1007/s11214-006-9051-8, 2006.

Lohmann, U. and Feichter, J.: Global indirect aerosol effects: a review, Atmos. Chem. Phys. Discuss., 4(6), 7561-7614, doi:10.5194/acpd-4-7561-2004, 2004.

McComiskey, A. and Feingold, G.: The scale problem in quantifying aerosol indirect effects, Atmos. Chem. Phys., 12(2), 1031-1049, doi:10.5194/acp-12-1031-2012, 2012.

McComiskey, A., Feingold, G., Frisch, A. S., Turner, D. D., Miller, M. A., Chiu, J. C., Min, Q. and Ogren, J. A.: An assessment of aerosol-cloud interactions in marine stratus clouds based on surface remote sensing, J. Geophys. Res. Atmos., 
114(9), 1-15, doi:10.1029/2008JD011006, 2009.

Mishra, M. K., Rajeev, K., Thampi, B. V., Parameswaran, K. and Nair, A. K. M.: Micro pulse lidar observations of mineral dust layer in the lower troposphere over the southwest coast of Peninsular India during the Asian summer monsoon season, J. Atmos. Solar-Terrestrial Phys., 72(17), 1251-1259, doi:10.1016/j.jastp.2010.08.012, 2010.

Murphy, D. M. and Koop, T.: Review of the vapour pressures of ice and supercooled water for atmospheric applications, Q. J. R. Meteorol. Soc., 131(608), 1539-1565, doi:10.1256/qj.04.94, 2005.

Narendra Reddy, N., Venkat Ratnam, M., Basha, G. and Ravikiran, V.: Cloud vertical structure over a tropical station obtained using long-term high resolution Radiosonde measurements, Atmos. Chem. Phys. Discuss., 1-49, doi:10.5194/acp2018-194, 2018.

Pandit, A. K., Gadhavi, H., Ratnam, M. V., Jayaraman, A., Raghunath, K. and Rao, S. V. B.: Characteristics of cirrus clouds and tropical tropopause layer: Seasonal variation and long-term trends, J. Atmos. Solar-Terrestrial Phys., 121(PB), 248-256, doi:10.1016/j.jastp.2014.07.008, 2014.

Pandit, A. K., Gadhavi, H. S., Ratnam, M. V., Raghunath, K., Rao, S. V. B. and Jayaraman, A.: Long-term trend analysis and climatology of tropical cirrus clouds using 16 years of lidar data set over Southern India, Atmos. Chem. Phys., 15(24), 13833-13848, doi:10.5194/acp-15-13833-2015, 2015.

Pandithurai, G., Takamura, T., Yamaguchi, J., Miyagi, K., Takano, T., Ishizaka, Y., Dipu, S. and Shimizu, A.: Aerosol effect on cloud droplet size as monitored from surface-based remote sensing over East China Sea region, Geophys. Res. Lett., 36(13), 1-5, doi:10.1029/2009GL038451, 2009.

Prasad, P., Raman, M. R., Ratnam, M. V., Ravikiran, V., Madhavan, B. L. and Bhaskara, S. V.: Nocturnal, seasonal and intra-annual variability of tropospheric aerosols observed using ground-based and space-borne lidars over a tropical location of India, Atmos. Environ., 213(May), 185-198, doi:10.1016/j.atmosenv.2019.06.008, 2019.

Radke, L. F., Coakley, J. A. and King, M. D.: Direct and remote sensing observations of the effects of ships on clouds, Science (80-. )., 246(4934), 1146-1149, doi:10.1126/science.246.4934.1146, 1989.

Rao, P. B., Jain, A. R., Kishore, P., Balamuralidhar, P., Damle, S. H. and Viswanathan, G.: Indian MST radar 1. System description and sample vector wind measurements in ST mode, Radio Sci., 30(4), 1125-1138, doi:10.1029/95RS00787, 1995.

Ratnam, M. V., Prasad, P., Raman, M. R., Ravikiran, V., Bhaskara, S. V., Murthy, B. V. K. and Jayaraman, A.: Role of dynamics on the formation and maintenance of the elevated aerosol layer during monsoon season over south-east peninsular India, , 188(June), 43-49, doi:10.1016/j.atmosenv.2018.06.023, 2018.

Redemann, J., Wood, R., Zuidema, P., Doherty, S., Luna, B., LeBlanc, S., Diamond, M., Shinozuka, Y., Chang, I., Ueyama, R., Pfister, L., Ryoo, J., Dobracki, A., da Silva, A., Longo, K., Kacenelenbogen, M., Flynn, C., Pistone, K., Knox, N., Piketh, S., Haywood, J., Formenti, P., Mallet, M., Stier, P., Ackerman, A., Bauer, S., Fridlind, A., Carmichael, G., Saide, P., Ferrada, G., Howell, S., Freitag, S., Cairns, B., Holben, B., Knobelspiesse, K., Tanelli, S., L’Ecuyer, T., Dzambo, A., Sy, O., McFarquhar, G., Poellot, M., Gupta, S., O’Brien, J., Nenes, A., Kacarab, M., Wong, J., Small-Griswold, J., Thornhill, K., 
Noone, D., Podolske, J., Schmidt, K. S., Pilewskie, P., Chen, H., Cochrane, S., Sedlacek, A., Lang, T., Stith, E., SegalRozenhaimer, M., Ferrare, R., Burton, S., Hostetler, C., Diner, D., Platnick, S., Myers, J., Meyer, K., Spangenberg, D., Maring, H. and Gao, L.: An overview of the ORACLES (ObseRvations of Aerosols above CLouds and their intEractionS) project: aerosol-cloud-radiation interactions in the Southeast Atlantic basin, Atmos. Chem. Phys., 1-82, doi:10.5194/acp2020-449, 2020.

Rosen, J. M. and Kjome, N. T.: Backscattersonde: a new instrument for atmospheric aerosol research, Appl. Opt., 30(12), 1552, doi:10.1364/ao.30.001552, 1991.

Rosenfeld, D., Lohmann, U., Raga, G. B., O’Dowd, C. D., Kulmala, M., Fuzzi, S., Reissell, A. and Andreae, M. O.: Flood or drought: How do aerosols affect precipitation?, Science (80-. )., 321(5894), 1309-1313, doi:10.1126/science.1160606, 2008. Rosenfeld, D., Sherwood, S., Wood, R. and Donner, L.: Climate Effects of Aerosol-Cloud Interactions, Science (80-. )., 343(6169), 379 LP - 380, doi:10.1126/science.1247490, 2014a.

Rosenfeld, D., Andreae, M. O., Asmi, A., Chin, M., Leeuw, G., Donovan, D. P., Kahn, R., Kinne, S., Kivekäs, N., Kulmala, M., Lau, W., Schmidt, K. S., Suni, T., Wagner, T., Wild, M. and Quaas, J.: Reviews of Geophysics, , 1-59, doi:10.1002/2013RG000441.Received, 2014b.

Sarna, K. and Russchenberg, H. W. J.: Ground-based remote sensing scheme for monitoring aerosol-cloud interactions, Atmos. Meas. Tech., 9(3), 1039-1050, doi:10.5194/amt-9-1039-2016, 2016.

Sarna, K. and Russchenberg, H. W. J.: Monitoring aerosol-cloud interactions at the CESAR Observatory in the Netherlands, Atmos. Meas. Tech., 10(5), 1987-1997, doi:10.5194/amt-10-1987-2017, 2017.

Sathiyamoorthy, V., Mahesh, C., Gopalan, K., Prakash, S., Shukla, B. P. and Mathur, A. K.: Characteristics of low clouds over the Arabian Sea, , 118(December), 489-503, doi:10.1002/2013JD020553, 2013.

Schmidt, J., Ansmann, A., Bühl, J., Baars, H., Wandinger, U., Müller, D. and Malinka, A. V.: Dual-FOV raman and Doppler lidar studies of aerosol-cloud interactions: Simultaneous profiling of aerosols, warm-cloud properties, and vertical wind, J. Geophys. Res., 119(9), 5512-5527, doi:10.1002/2013JD020424, 2014.

Schmidt, J., Ansmann, A., Bühl, J. and Wandinger, U.: Strong aerosol-cloud interaction in altocumulus during updraft periods: Lidar observations over central Europe, Atmos. Chem. Phys., 15(18), 10687-10700, doi:10.5194/acp-15-106872015, 2015.

Seinfeld, J. H., Bretherton, C., Carslaw, K. S., Coe, H., DeMott, P. J., Dunlea, E. J., Feingold, G., Ghan, S., Guenther, A. B., Kahn, R., Kraucunas, I., Kreidenweis, S. M., Molina, M. J., Nenes, A., Penner, J. E., Prather, K. A., Ramanathan, V., Ramaswamy, V., Rasch, P. J., Ravishankara, A. R., Rosenfeld, D., Stephens, G. and Wood, R.: Improving our fundamental understanding of the role of aerosol-cloud interactions in the climate system, Proc. Natl. Acad. Sci. U. S. A., 113(21), 57815790, doi:10.1073/pnas.1514043113, 2016.

Sena, E. T., McComiskey, A. and Feingold, G.: A long-term study of aerosol-cloud interactions and their radiative effect at the Southern Great Plains using ground-based measurements, Atmos. Chem. Phys., 16(17), 11301-11318, doi:10.5194/acp16-11301-2016, 2016. 
https://doi.org/10.5194/amt-2021-410

Preprint. Discussion started: 22 December 2021

(C) Author(s) 2021. CC BY 4.0 License.
Atmospheric

Measurement

Techniques

Discussions

Small, J. D., Chuang, P. Y., Feingold, G. and Jiang, H.: Can aerosol decrease cloud lifetime?, Geophys. Res. Lett., 36(16), 1-5, doi:10.1029/2009GL038888, 2009.

Srinivasulu, P., Yasodha, P., Kamaraj, P., Rao, T. N., Jayaraman, A., Reddy, S. N. and Satyanarayana, S.: 1280-MHz active array radar wind profiler for lower atmosphere: System description and data validation, J. Atmos. Ocean. Technol., 29(10), 1455-1470, doi:10.1175/JTECH-D-12-00030.1, 2012.

Stein, A. F., Draxler, R. R., Rolph, G. D., Stunder, B. J. B., Cohen, M. D. and Ngan, F.: Noaa's hysplit atmospheric transport and dispersion modeling system, Bull. Am. Meteorol. Soc., 96(12), 2059-2077, doi:10.1175/BAMS-D-14-00110.1, 2015.

Twomey, S.: The Influence of Pollution on the Shortwave Albedo of Clouds, J. Atmos. Sci., 34(7), 1149-1152, doi:10.1175/1520-0469(1977)034<1149:TIOPOT>2.0.CO;2, 1977.

Vernier, J., Fairlie, T. D., Natarajan, M., Wienhold, F. G., Bian, J., Martinsson, B. G., Crumeyrolle, S., Thomason, L. W. and Bedka, K. M.: Journal of Geophysical Research : Atmospheres, , doi:10.1002/2014JD022372.Received, 2015.

Vernier, J. P., Fairlie, T. D., Deshler, T., Venkat Ratnam, M., Gadhavi, H., Kumar, B. S., Natarajan, M., Pandit, A. K., Akhil Raj, S. T., Hemanth Kumar, A., Jayaraman, A., Singh, A. K., Rastogi, N., Sinha, P. R., Kumar, S., Tiwari, S., Wegner, T., Baker, N., Vignelles, D., Stenchikov, G., Shevchenko, I., Smith, J., Bedka, K., Kesarkar, A., Singh, V., Bhate, J., Ravikiran, V., Durga Rao, M., Ravindrababu, S., Patel, A., Vernier, H., Wienhold, F. G., Liu, H., Knepp, T. N., Thomason, L., Crawford, J., Ziemba, L., Moore, J., Crumeyrolle, S., Williamson, M., Berthet, G., Jégou, F. and Renard, J. B.: BATAL: The balloon measurement campaigns of the Asian tropopause aerosol layer, Bull. Am. Meteorol. Soc., 99(5), 955-973, doi:10.1175/BAMS-D-17-0014.1, 2018.

Vernier, J. P., Kalnajs, L., Diaz, J. A., Reese, T., Corrales, E., Alan, A., Vernier, H., Holland, L., Patel, A., Rastogi, N., Wienhold, F., Carn, S., Krotkov, N. and Murray, J.: VolKilau: Volcano rapid response balloon campaign during the 2018 Kilauea eruption, Bull. Am. Meteorol. Soc., 101(10), E1602-E1618, doi:10.1175/BAMS-D-19-0011.1, 2020.

Weinzierl, B., Ansmann, A., Prospero, J. M., Althausen, D., Benker, N., Chouza, F., Dollner, M., Farrell, D., Fomba, W. K., Freudenthaler, V., Gasteiger, J., Groß, S., Haarig, M., Heinold, B., Kandler, K., Kristensen, T. B., Mayol-Bracero, O. L., Müller, T., Reitebuch, O., Sauer, D., Schäfler, A., Schepanski, K., Spanu, A., Tegen, I., Toledano, C. and Walser, A.: The Saharan aerosol long-range transport and aerosol-cloud-interaction experiment: Overview and selected highlights, Bull. Am. Meteorol. Soc., 98(7), 1427-1451, doi:10.1175/BAMS-D-15-00142.1, 2017.

Wiegner, M., Madonna, F., Binietoglou, I., Forkel, R., Gasteiger, J., Geiß, A., Pappalardo, G., Schäfer, K. and Thomas, W.: What is the benefit of ceilometers for aerosol remote sensing? An answer from EARLINET, Atmos. Meas. Tech., 7(7), 1979-1997, doi:10.5194/amt-7-1979-2014, 2014.

Winker, D. M., Hunt, W. H. and McGill, M. J.: Initial performance assessment of CALIOP, Geophys. Res. Lett., 34(19), 15, doi:10.1029/2007GL030135, 2007. 


\section{Tables}

Table 1. List of instruments deployed (in BACIS) and the corresponding physical parameters obtained.

SI. Instrument Purpose

No.

1

CALIPSO

Aerosol and cloud profiling

2 MPL

3 Mie Lidar

4 COBALD

5 CPS

6 MST Radar

3-D Wind components, turbulence

$7 \quad$ LAWP

3-D Wind components, turbulence

$8 \quad$ MWR

Meteorological parameters and cloud

9 ICON

Ambient aerosol

$10 \quad$ Ceilometer

Aerosol and cloud profiling

Aerosol and cloud profiling

In-situ measurement of aerosol and cloud particles
In situ measurement of cloud particles

\section{1}

982

983

984

985

986

987

988

989

990

991

992

993

994

995

996

\section{Physical quantity (Unit)}

Total attenuated backscatter $\left(\mathrm{km}^{-1}\right.$ $\mathrm{sr}^{-1}$ )

Backscatter coefficient $\left(\mathrm{m}^{-1} \mathrm{sr}^{-1}\right)$

Backscatter coefficient $\left(\mathrm{km}^{-1} \mathrm{sr}^{-1}\right)$

Backscatter ratio

Cloud particle number

concentration(\#/cc), degree of polarization(DOP)

Horizontal and vertical wind components $(\mathrm{m} / \mathrm{s})$

Horizontal and vertical wind components $(\mathrm{m} / \mathrm{s})$

Temperature $\left({ }^{0} \mathrm{C}\right), \mathrm{RH}(\%)$ and cloud liquid water content $\left(\mathrm{g} / \mathrm{m}^{3}\right)$

BC concentration $\left(\mu \mathrm{g} / \mathrm{m}^{3}\right)$,

Scattering coefficient and absorption coefficient $\left(\mathrm{m}^{-1}\right)$ Back scatter coefficient $\left(\mathrm{km}^{-1} \mathrm{sr}^{-1}\right)$ 
997 Table. 2. Date and time of BACIS campaigns and the instruments operated during the corresponding campaign.

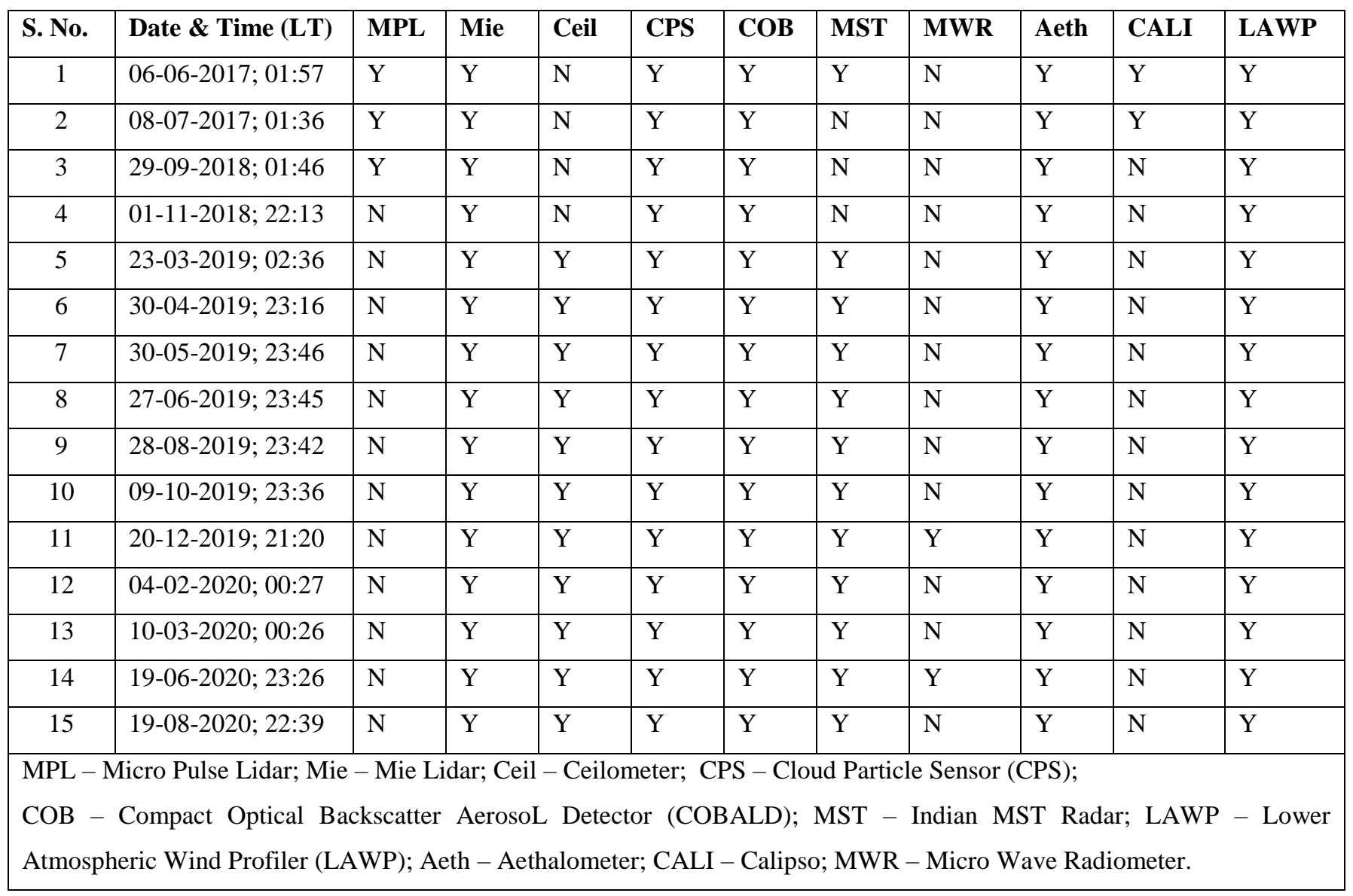


Table 3. Color Index (CI) and other physical parameters of the ice clouds. Backscatter ratio (BSR) in normal (Italic) font is for $450 \mathrm{~nm}(940 \mathrm{~nm})$ channel.

1003

\begin{tabular}{|c|c|c|c|c|c|c|c|}
\hline Date & $\begin{array}{l}\text { Campaign } \\
\text { no }\end{array}$ & $\begin{array}{l}\text { Ice } \\
\text { cloud } \\
\text { altitude } \\
(\mathbf{k m})\end{array}$ & $\begin{array}{l}\text { Temperatur } \\
\text { e range }\left({ }^{0} \mathrm{C}\right)\end{array}$ & $\begin{array}{l}\text { RH } \\
\text { condition }\end{array}$ & $\begin{array}{l}\text { Mean } \\
\text { (median) } \\
\text { CI }\end{array}$ & $\begin{array}{l}\text { Mean } \\
\text { (median) } \\
\text { BSR }\end{array}$ & $\begin{array}{l}\text { Range of } \\
\text { peak ice } \\
\text { particle no } \\
\text { conc. (\#/cc) }\end{array}$ \\
\hline 06-Jun-2017 & 1 & $13-15.5$ & -53 to -74 & $\sim \mathrm{SRH}$ & $\begin{array}{l}19.2 \\
(19.2)\end{array}$ & $\begin{array}{l}5.6(4.8) \\
90.4(73) \\
\end{array}$ & $10^{-2}$ to $10^{-1}$ \\
\hline 08-Jul-2017 & 2 & $10.5-16$ & -34 to -78 & $>\mathrm{SRH}$ & $18.7(18.6)$ & $\begin{array}{l}3(2.9) \\
37.5(35.2)\end{array}$ & $10^{-2}$ to $10^{-1}$ \\
\hline 01-Nov-2018 & 4 & $12-12.6$ & -47 to -53 & $>\mathrm{SRH}$ & 19.5 & $\begin{array}{l}17.2(17.5) \\
318(313.5)\end{array}$ & $10^{-1}$ to 1 \\
\hline 30-Apr-2019 & 6 & $9.3-16$ & -22 to -79 & $\sim \mathrm{SRH}$ & 19.4(19.3) & $\begin{array}{l}16.4(8.6) \\
302(147) \\
\end{array}$ & $10^{-1}$ to 1 \\
\hline 30-Мау-2019 & 7 & $\begin{array}{l}16.2- \\
17.4 \\
\end{array}$ & -78 to -84.5 & $<\mathrm{SRH}$ & 18 & $\begin{array}{l}1.6(1.4) \\
12.2(8.7)\end{array}$ & $10^{-3}$ to $10^{-2}$ \\
\hline 27-Jun-2019 & 8 & $9.4-10.7$ & $\begin{array}{l}-23.7 \text { to } \\
-35.2\end{array}$ & $>\mathrm{SRH}$ & 19.3(17.9) & $\begin{array}{l}5.1(3.1) \\
74.8(43.2)\end{array}$ & $10^{-1}$ to 1 \\
\hline 19-Jun-2020 & 14 & $\begin{array}{l}14.2- \\
15.4\end{array}$ & -62 to -75 & $<\mathrm{SRH}$ & 21 & $\begin{array}{l}7.9(7.9) \\
147.4(143.2)\end{array}$ & $10^{-1}$ to 1 \\
\hline
\end{tabular}


Table 4. Color Index (CI) and backscatter ratio (BSR) of non-spherical (coarse) particle layers as identified by CPS 1010 sonde. The BSR in normal (italic) font is for $450 \mathrm{~nm}(940 \mathrm{~nm})$. Blue (red) color values are observed in the monsoon (pre-monsoon) months.

\begin{tabular}{|l|l|l|l|l|l|}
\hline $\begin{array}{l}\text { Campaign } \\
\text { Date }\end{array}$ & $\begin{array}{l}\text { Non- } \\
\text { spherical } \\
\text { layer } \\
\text { altitude }(\mathbf{k m})\end{array}$ & $\begin{array}{l}\text { Temperature } \\
\left.\text { range } \mathbf{(}^{\mathbf{0}} \mathbf{C}\right)\end{array}$ & $\begin{array}{l}\text { RH } \\
\text { range } \\
\mathbf{( \% )}\end{array}$ & $\begin{array}{l}\text { Mean } \\
\text { (median) } \\
\text { CI }\end{array}$ & $\begin{array}{l}\text { Mean } \\
\text { (median) BSR }\end{array}$ \\
\hline 06-Jun-2017 & $0.5-2.5$ & 27.6 to 15.5 & $63.5-81.3$ & $12.3(12.5)$ & $\begin{array}{l}1.45(1.4) \\
6.5(6)\end{array}$ \\
\hline 08-Jul-2017 & $0.5-2.5$ & 25.3 to 14.7 & $64.2-96.4$ & $14.6(14.8)$ & $\begin{array}{l}2 \\
15.8\end{array}$ \\
\hline 29-Sep-2018 & $0.5-1$ & 22.6 to 20 & $92-94$ & 12.3 & $\begin{array}{l}3.3(3.2) \\
30(29)\end{array}$ \\
\hline 27-Jun-2019 & $0.5-1.5$ & 27.6 to 19.8 & $57.3-70.3$ & 11.4 & $\begin{array}{l}1.6 \\
7.6\end{array}$ \\
\hline 19-Jun-2020 & $0.5-2.5$ & 28.8 to 14.2 & $57.2-94.4$ & $12.6(12.8)$ & $\begin{array}{l}1.6 \\
8(8.1)\end{array}$ \\
\hline 23-Mar-2019 & $1.5-3.5$ & 23 to 6.5 & $32.7-70.3$ & $12.6(12.8)$ & $\begin{array}{l}2 \\
13\end{array}$ \\
\hline 30-Apr-2019 & $0.5-4$ & 28 to 4.5 & $60.2-97.3$ & $12.2(12.6)$ & $\begin{array}{l}3.3(2.6) \\
28(21.5)\end{array}$ \\
\hline 30-May-2019 & $0.5-5$ & 28.8 to -0.1 & $60-98$ & $11.7(11.6)$ & $\begin{array}{l}3.2(2.9) \\
25.7(22)\end{array}$ \\
\hline
\end{tabular}


https://doi.org/10.5194/amt-2021-410

Preprint. Discussion started: 22 December 2021

(C) Author(s) 2021. CC BY 4.0 License.

\section{Atmospheric Measurement \\ Techniques \\ Discussions}

1013

1014

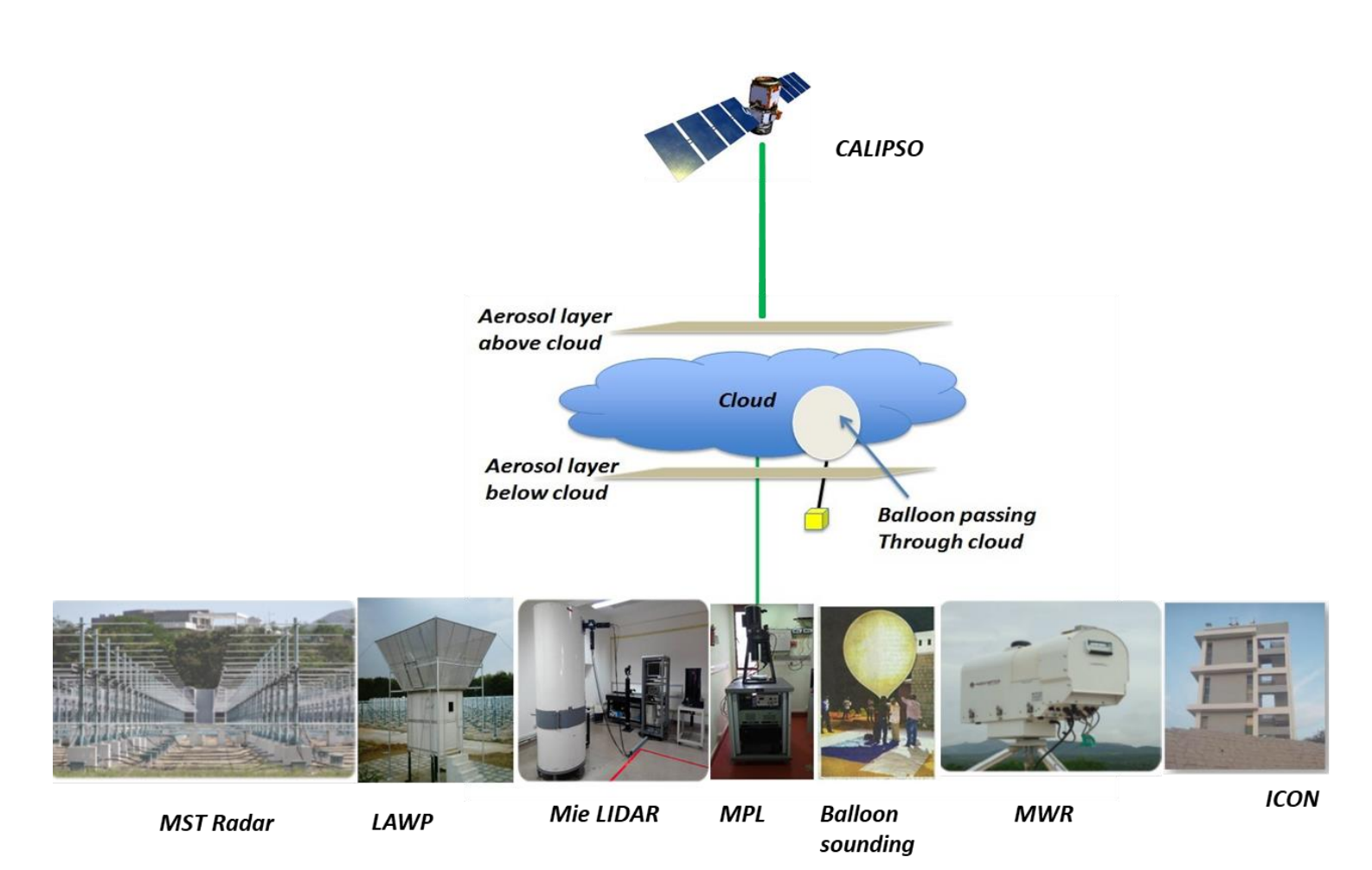

1015 1016 1017 1018 1019 1020 1021 1022 1023 1024 1025 1026 1027 1028 1029 1030 1031 1032 1033 1034 1035 1036 1037 1038 1039 1040

(1)

Figure 1. Schematic diagram showing the observational concept of Balloon borne Aerosol Cloud Interaction Studies (BACIS) campaign. 
https://doi.org/10.5194/amt-2021-410

Preprint. Discussion started: 22 December 2021

(c) Author(s) 2021. CC BY 4.0 License.
Atmospheric Measurement Techniques

Discussions
1042

1043

1044

1045

1046

1047

1048

1049

1050

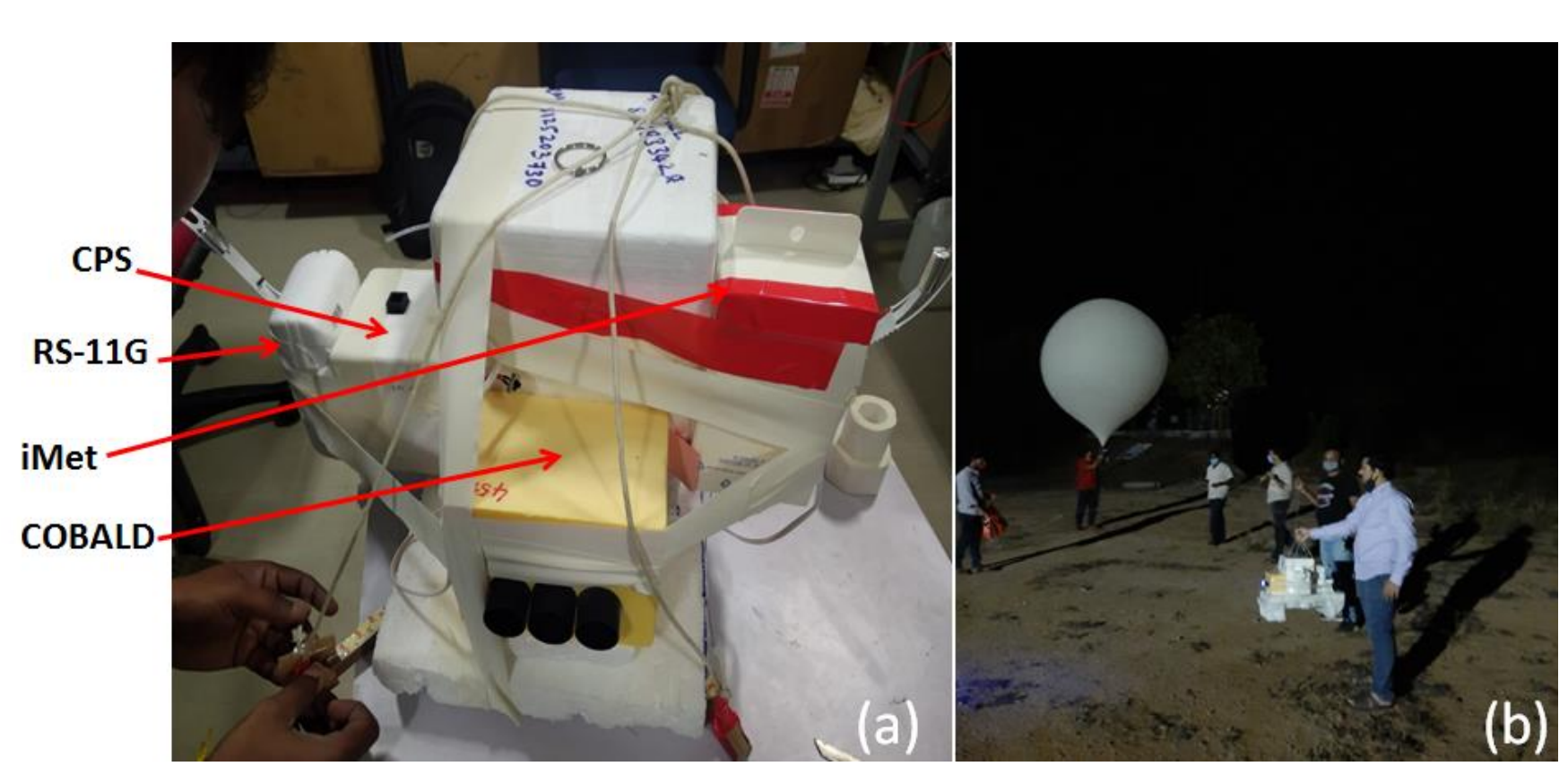

Figure 2. Photograph shows (a) the balloon payload with COBALD, iMet radiosonde, CPS, RS-11G radiosonde, and (b) pre-launch preparations at the launch field with payload and balloon. 
https://doi.org/10.5194/amt-2021-410

Preprint. Discussion started: 22 December 2021

(C) Author(s) 2021. CC BY 4.0 License.

\section{Atmospheric Measurement \\ Techniques \\ Discussions}

1051

1052

1053

1054

1055

1056

1057

1058

1059

1060

1061

1062

1063

1064

1065

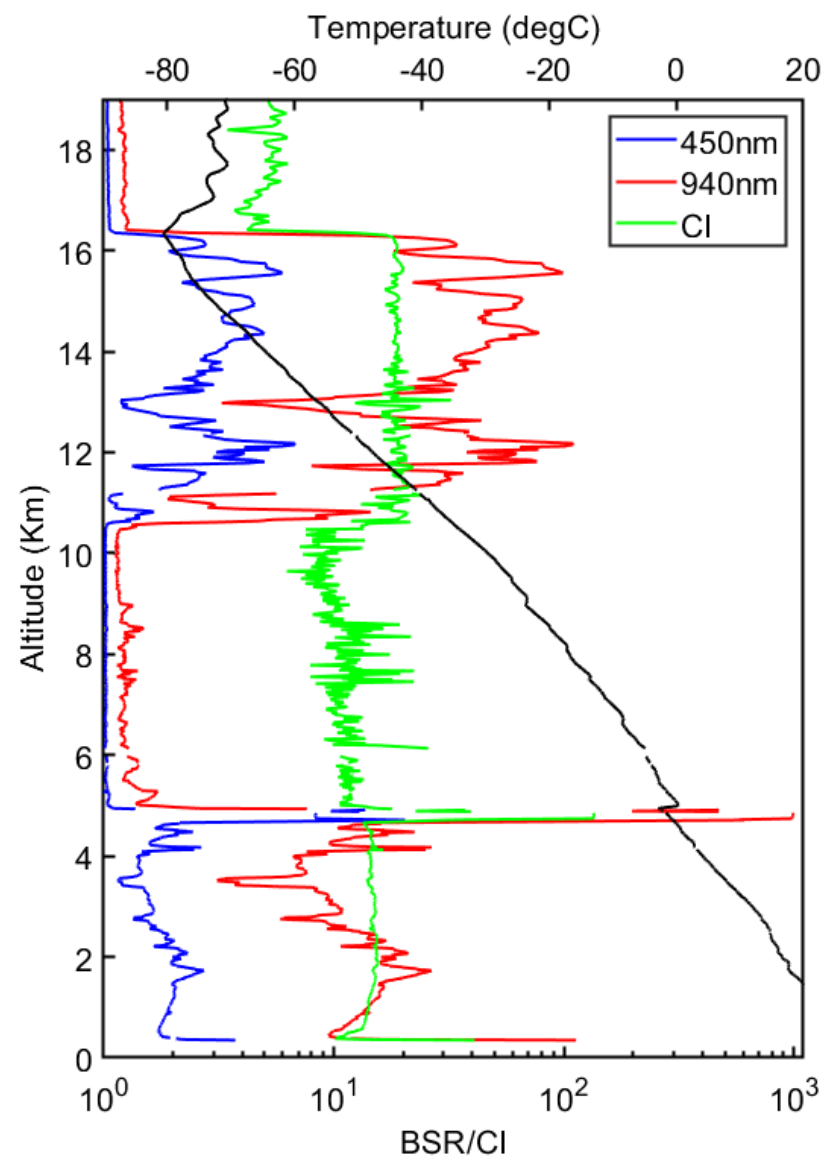

Figure 3. Backscatter ratio (BSR) at blue $(450 \mathrm{~nm})$ and red $(940 \mathrm{~nm})$ channels obtained using a COBALD sonde launched during the second pilot campaign (08 July 2017). Color Index (CI) estimated from BSR at both channels is also shown (in green color). 
https://doi.org/10.5194/amt-2021-410

Preprint. Discussion started: 22 December 2021

(c) Author(s) 2021. CC BY 4.0 License.
Atmospheric

Measurement

Techniques

Discussions
1066

1067

1068

1069

1070

1071

1072

1073

1074

1075

1076

1077

1078

1079

1080
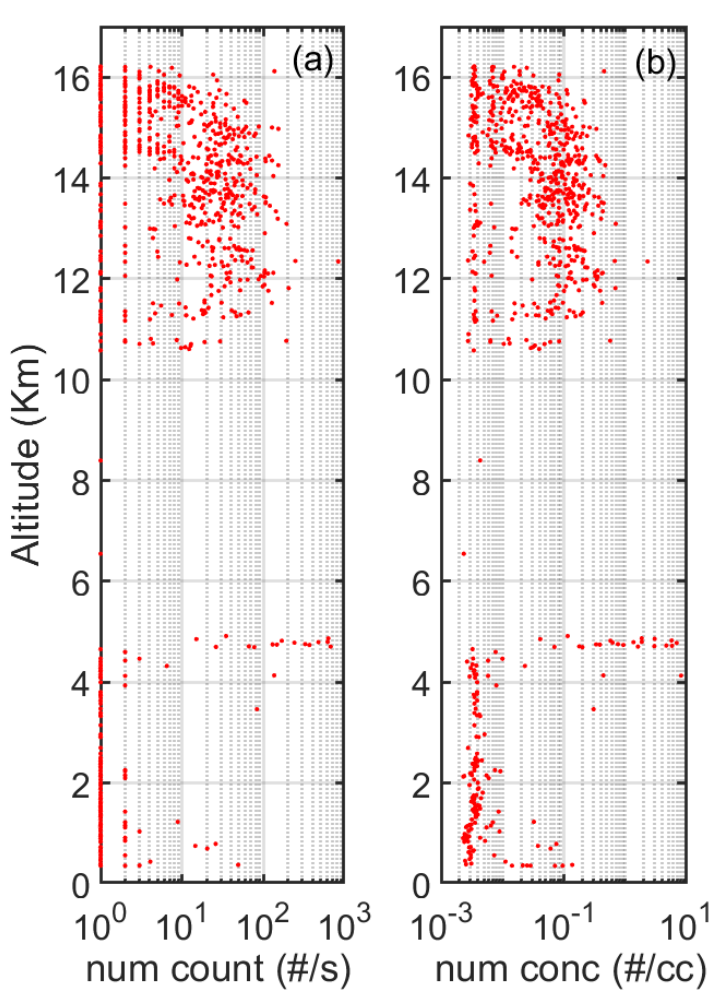

\section{8-July-2017}
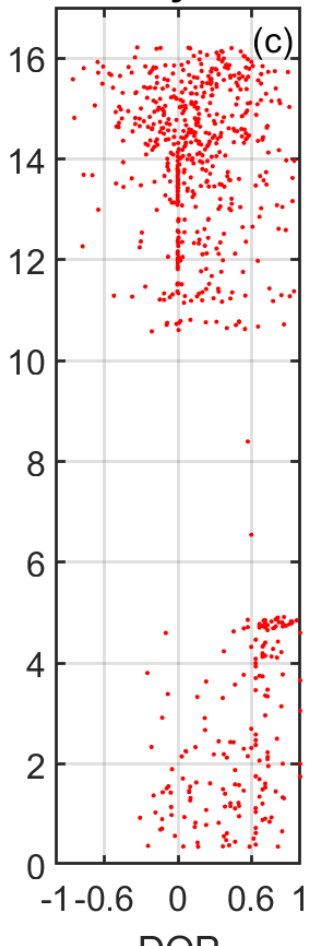

DOP
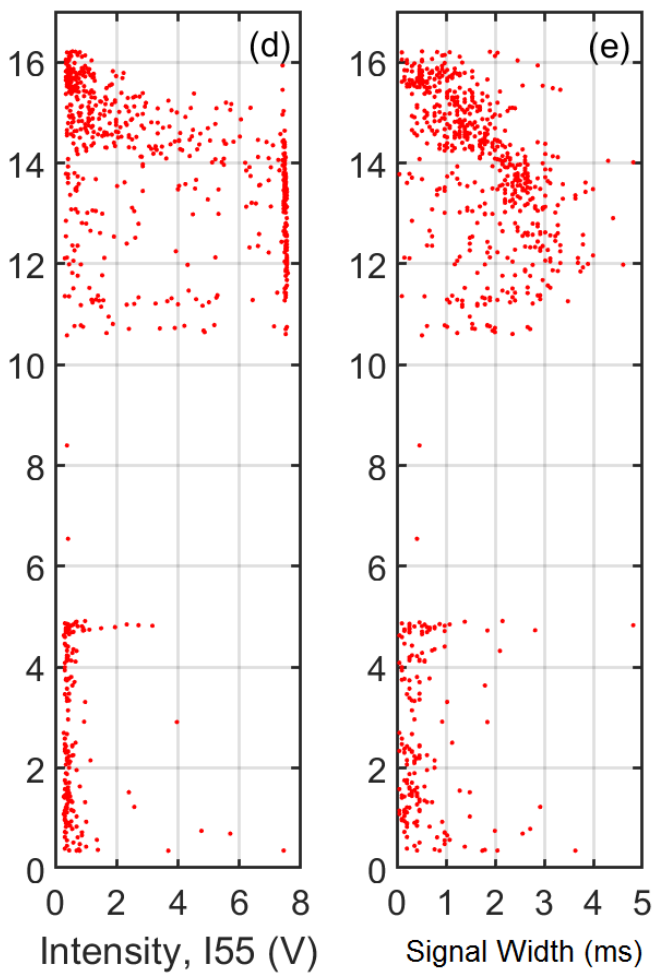

Figure 4. CPS measurements collected from the second pilot campaign (08 July 2017) showing (a) cloud particle number count (corrected), \#/s (b) cloud particle number concentration, $\# / \mathrm{cm}^{3}$ (c) Degree of polarization of a cloud particle, DOP (d) the intensity of light scattered at 55 degrees angle in Volts and (e) the particle signal width in ms. 

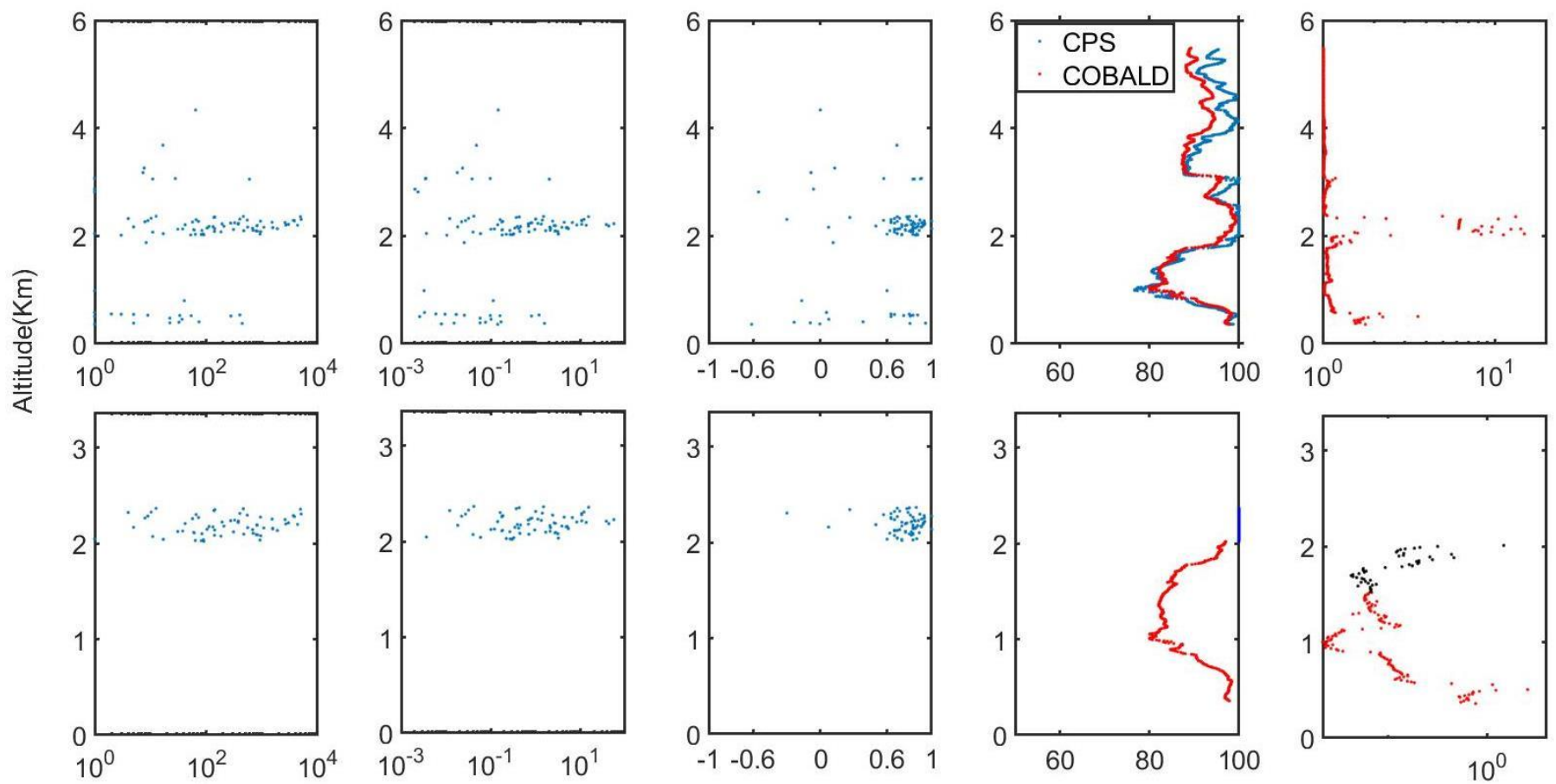

Figure 5. The top panel shows COBALD and CPS observations from a sounding held on 01 November 2018 up to the 1084 altitude of $6 \mathrm{~km}$ (as focus is on liquid cloud region). Bottom panel shows the same parameters but for the portion of the 1085 same profile where liquid cloud (blue dots) and aerosol (from cloud base to $500 \mathrm{~m}$ below) were identified by the scheme. 

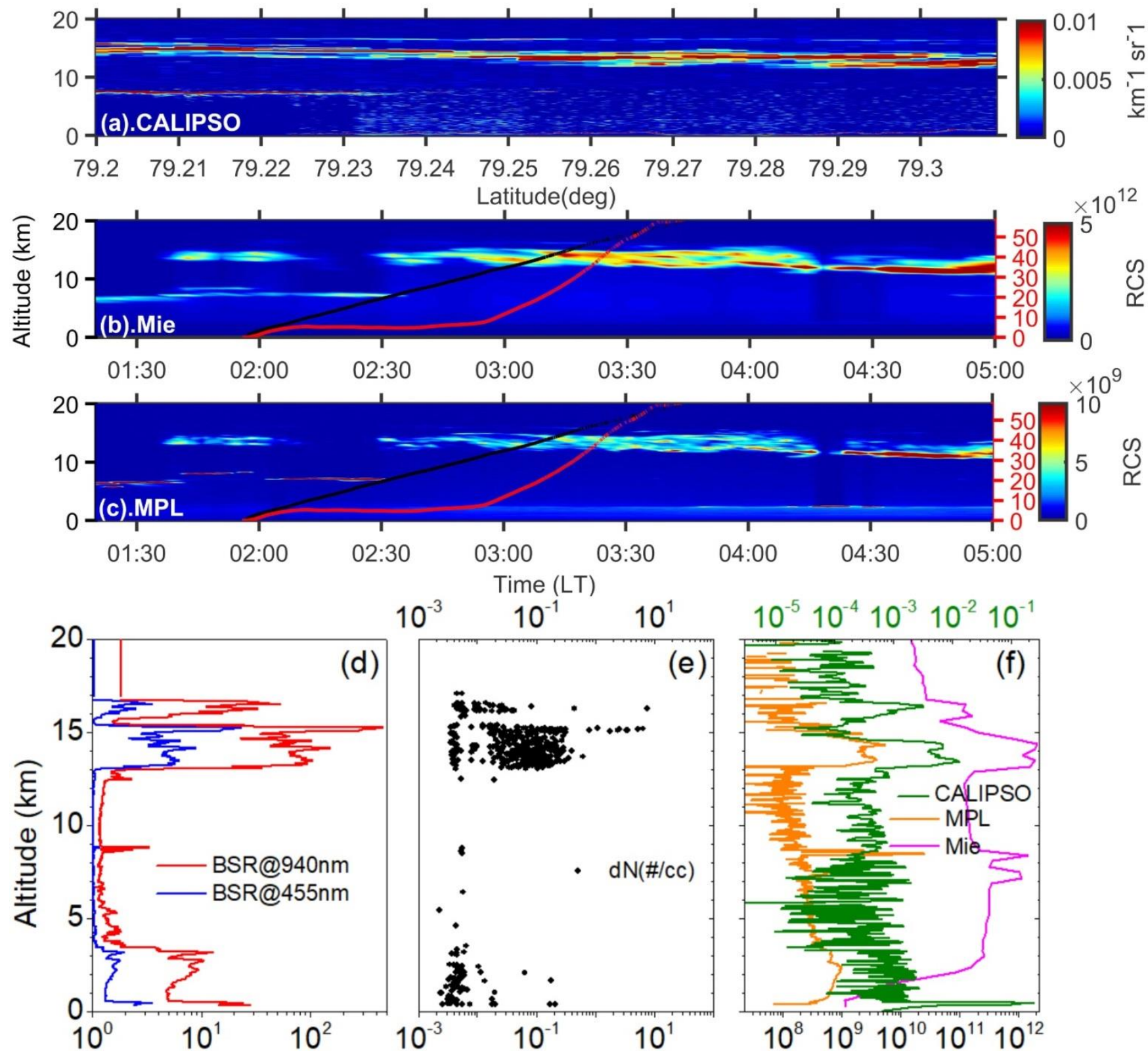

1088

Figure 6. Multi-instrument data from balloon sounding held on early hours of 06 June 2017. The total attenuated back scatter from (a) CALIPSO and temporal variation in range corrected signal from (b) Mie lidar (c) MPL. The red (black) lines over plotted on contour maps (b) and (c) represent balloon drift (altitude) in km with time. Drift as a function of time can be read with right y-axis (red font) and altitude as function of time can be read with left y-axis. The profiles of BSR at two channels from COBALD (blue and red colored lines), particle number concentration from CPS (black colored dots), RCS from MPL (orange), Mie lidar (magenta) and total attenuated back scatter from CALIPSO (olive green) lines shown in (d), (e) and (f) respectively. 
https://doi.org/10.5194/amt-2021-410

Preprint. Discussion started: 22 December 2021

(c) Author(s) 2021. CC BY 4.0 License.
Atmospheric Measurement

Techniques

(c) (1)

Discussions

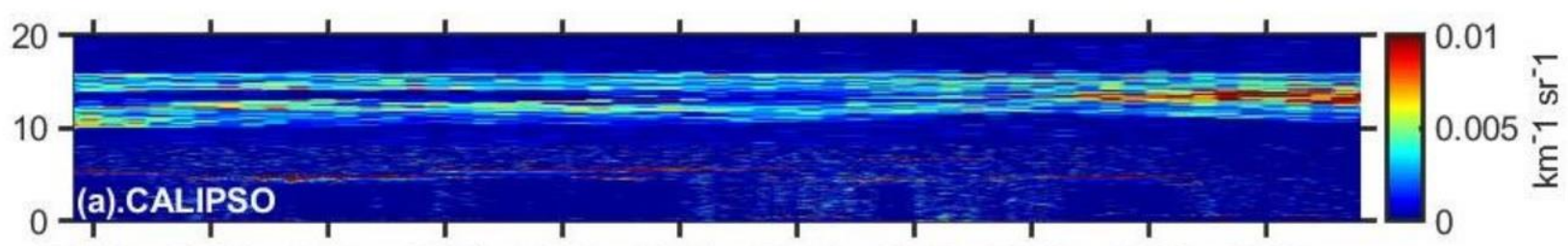

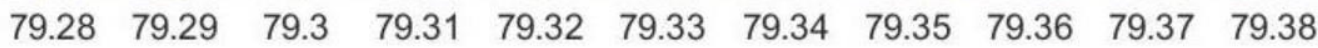

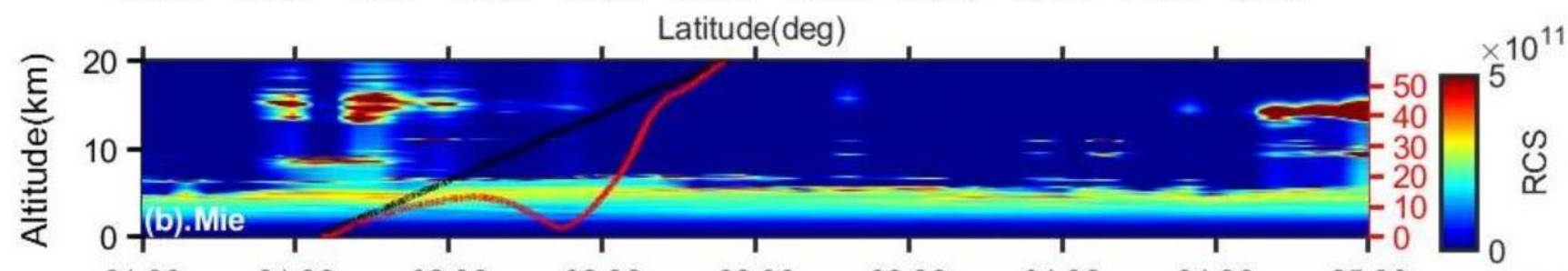

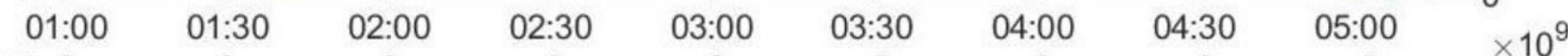

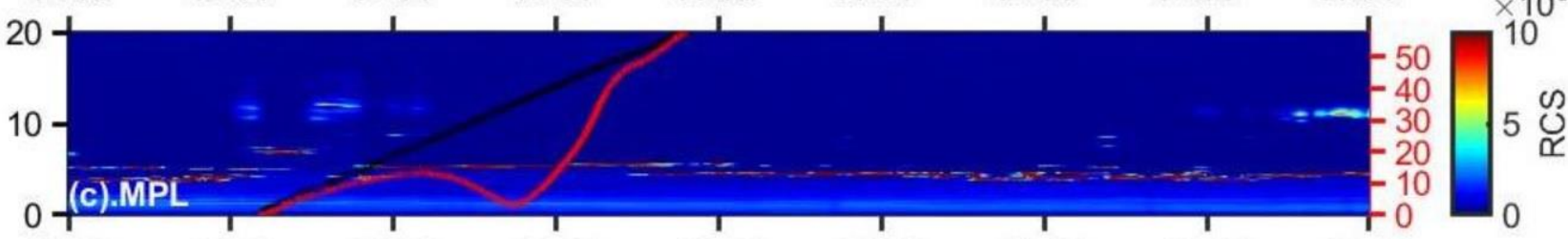

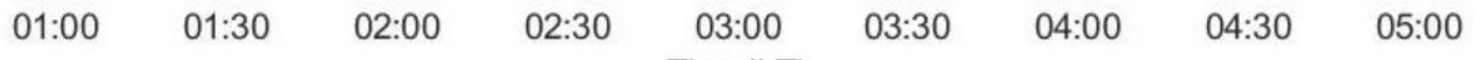

Time(LT)
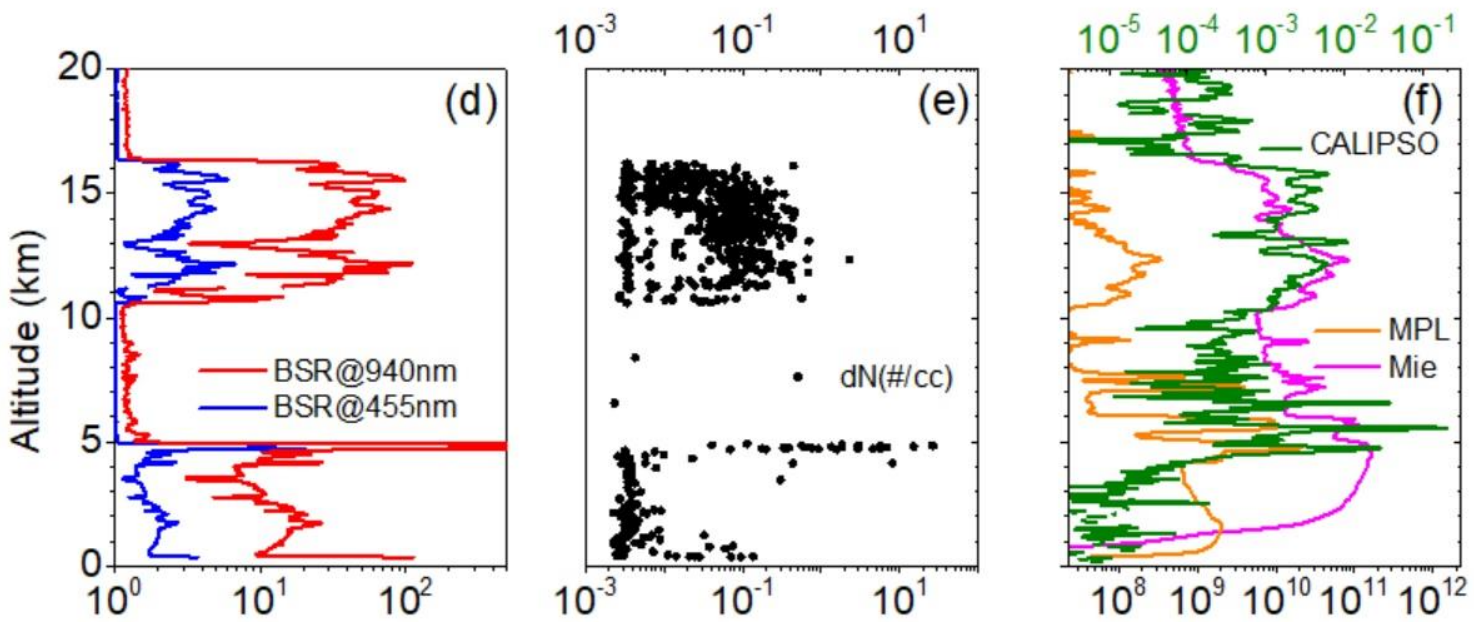

1098

1099

Figure 7. Same as Figure 6 but for the case of second pilot campaign (08 July2017). 
Indian MST Radar \& Radiosonde, Gadanki, 8 July 2017
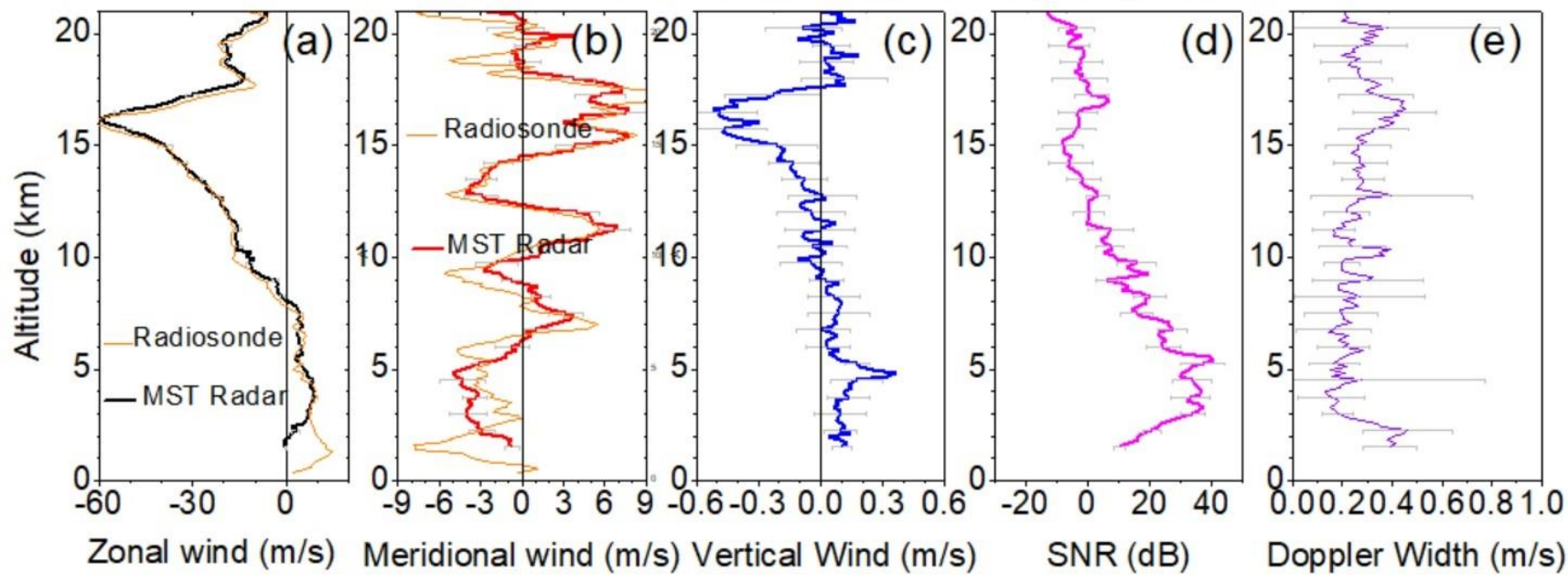

(f) MST Radar Vertical wind

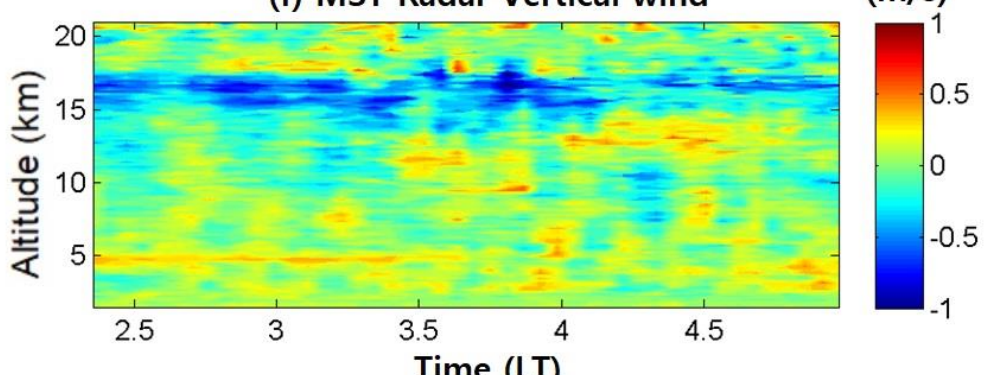

Figure 8. Profiles of (a) zonal wind, (b) meridional wind, (c) Vertical wind, (d) Signal to Noise Ratio (SNR) and (e) Doppler Width obtained from Indian MST radar during 8 July 2017 averaged during 02:30 LT to 03:30 LT. Horizontal bars show standard deviation. Radiosonde observed zonal and meridional winds are also superimposed in the respective panels. (f) Time-altitude section of vertical wind obtained from Indian MST radar during the radiosonde launch time. 
https://doi.org/10.5194/amt-2021-410

Preprint. Discussion started: 22 December 2021

(c) Author(s) 2021. CC BY 4.0 License.
Atmospheric

Measurement

Techniques

Discussions

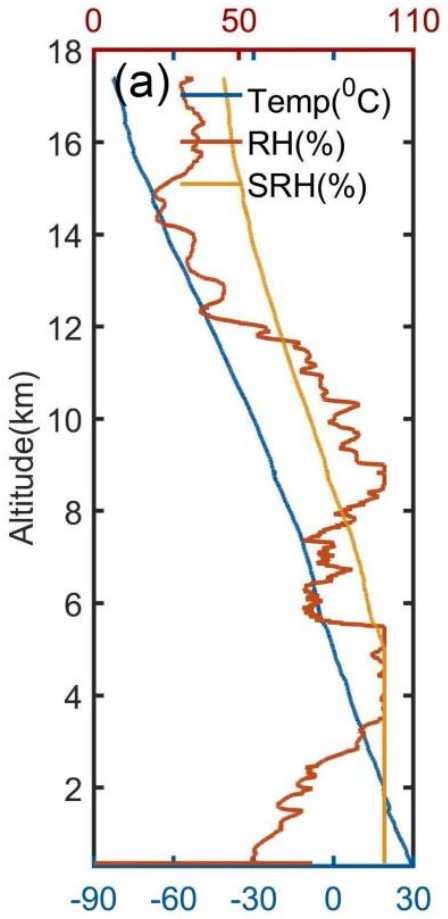

1109

1110

1111

1112

1113
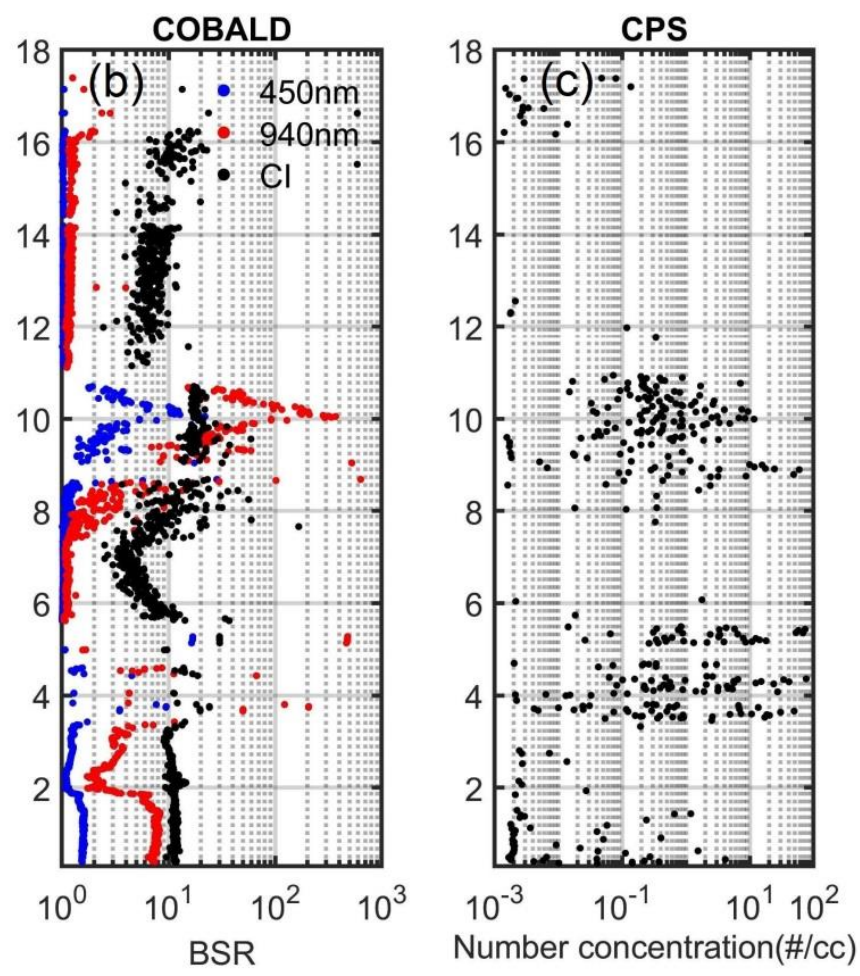

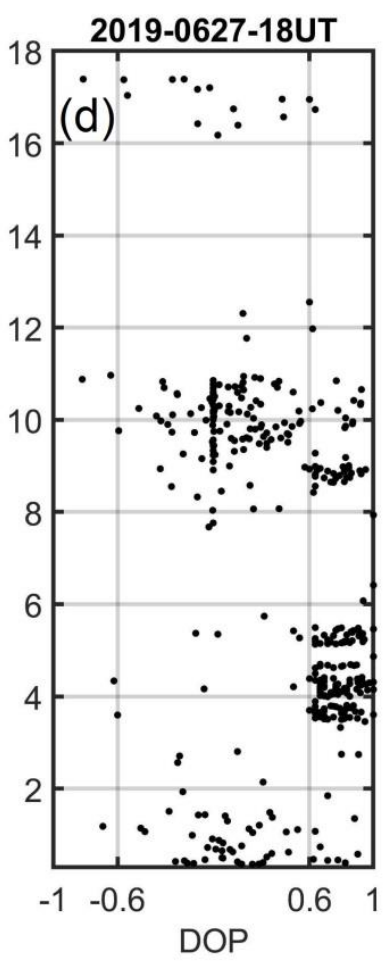

Figure 9. Combined observations of COBALD and CPS from balloon sounding held on 27 June 2019 at 2330 LT. (a) Temperature (T), Relative humidity (RH) and Saturation Relative Humidity (SRH) (b) Backscatter ratio at $455 \mathrm{~nm}$ (blue), $940 \mathrm{~nm}$ (red) and Color Index (Black). (c) cloud particle number concentration and (d) Degree of polarization (DOP). 

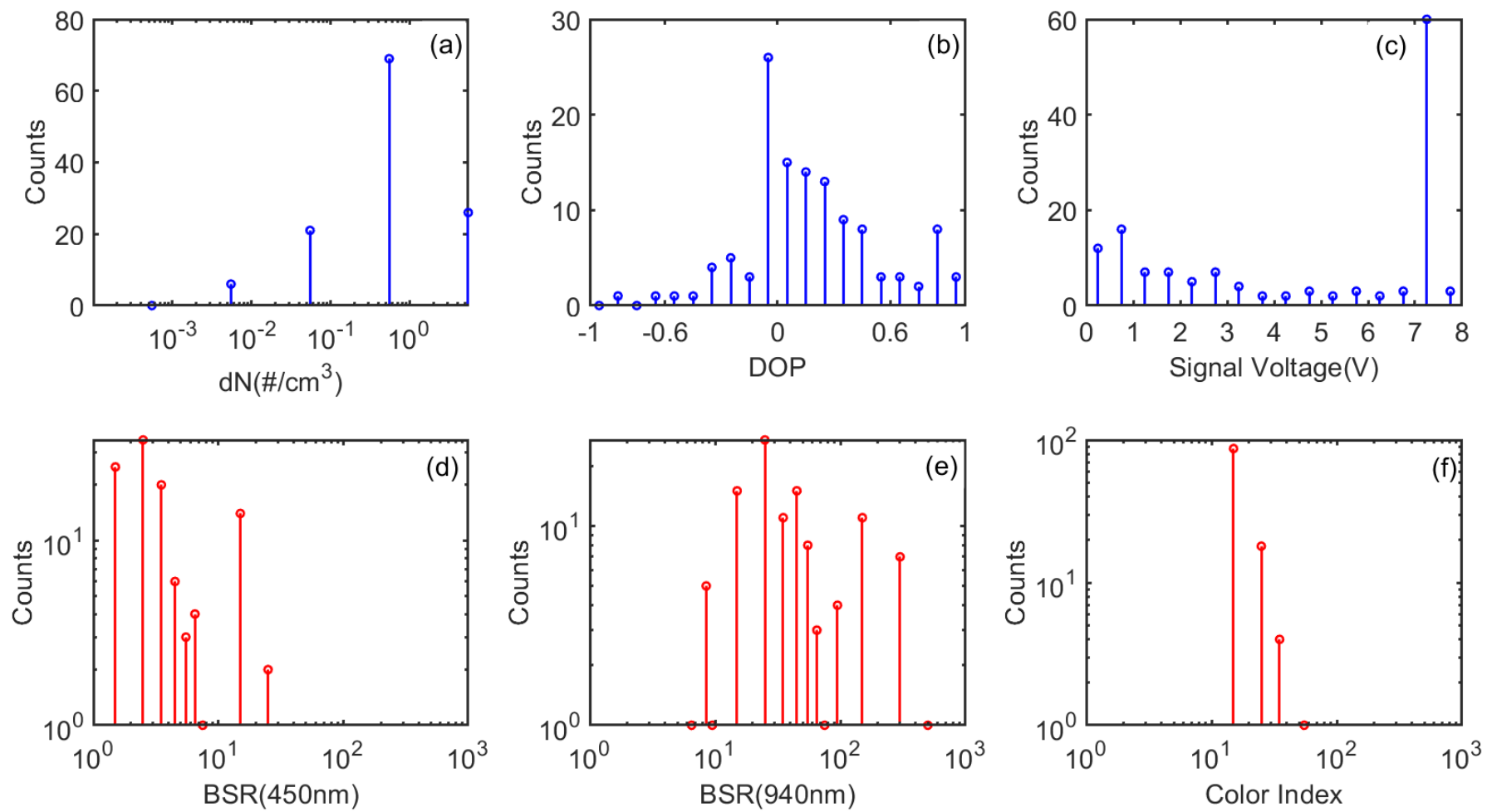

Figure 10. Histogram of (a) Droplet number concentration (dN) in \#/cc (b) Degree of polarization (DOP) (c) Backscattered signal (Volts) (d) Backscatter ratio at $455 \mathrm{~nm}$, (e) Backscatter ratio at $940 \mathrm{~nm}$ and (f) Color Index. The top panel shows the data from CPS and the bottom panel from COBALD for the ice cloud layer between 9 and $11 \mathrm{~km}$ from the sounding held on 27 June 2019. 
https://doi.org/10.5194/amt-2021-410

Preprint. Discussion started: 22 December 2021

(c) Author(s) 2021. CC BY 4.0 License.

(c) (i)
Atmospheric Measurement

Techniques

Discussions

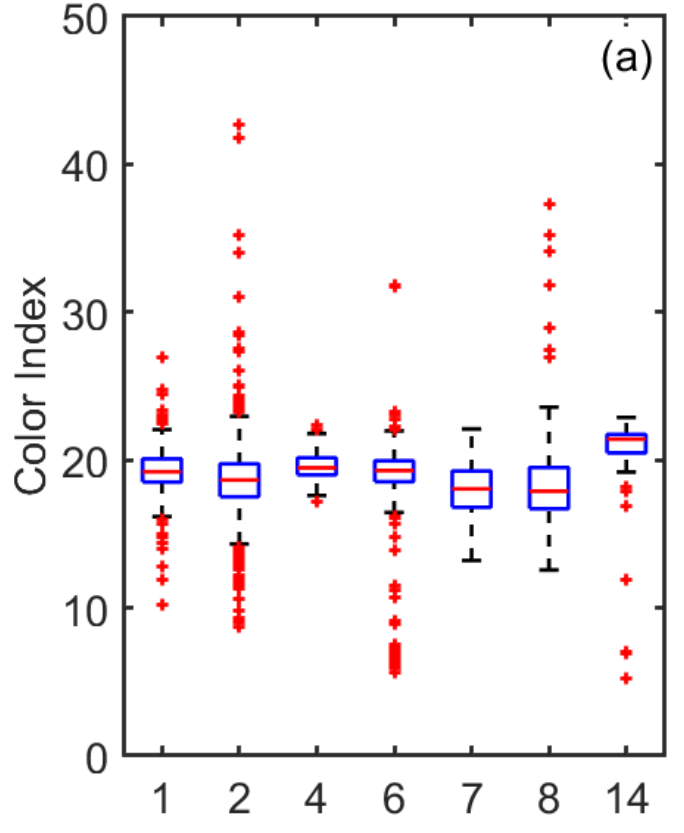

Campaign No.

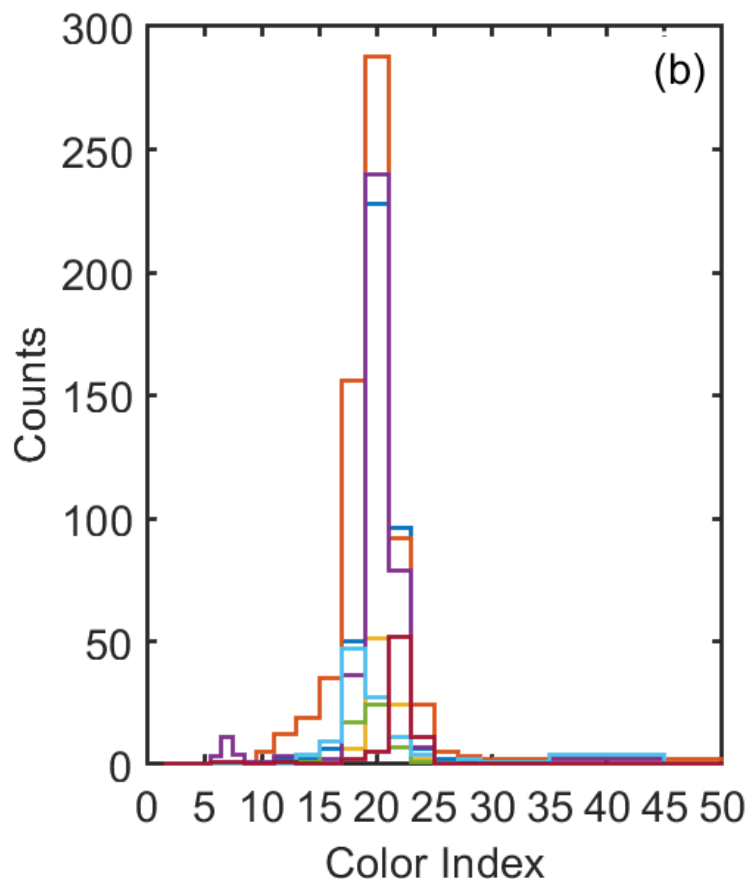

1125

1126

1127 1128

Figure 11. (a) The box plot of Color Index (CI) observed for the ice clouds found in different campaigns. (b) The histogram of the CI values from each campaign. 


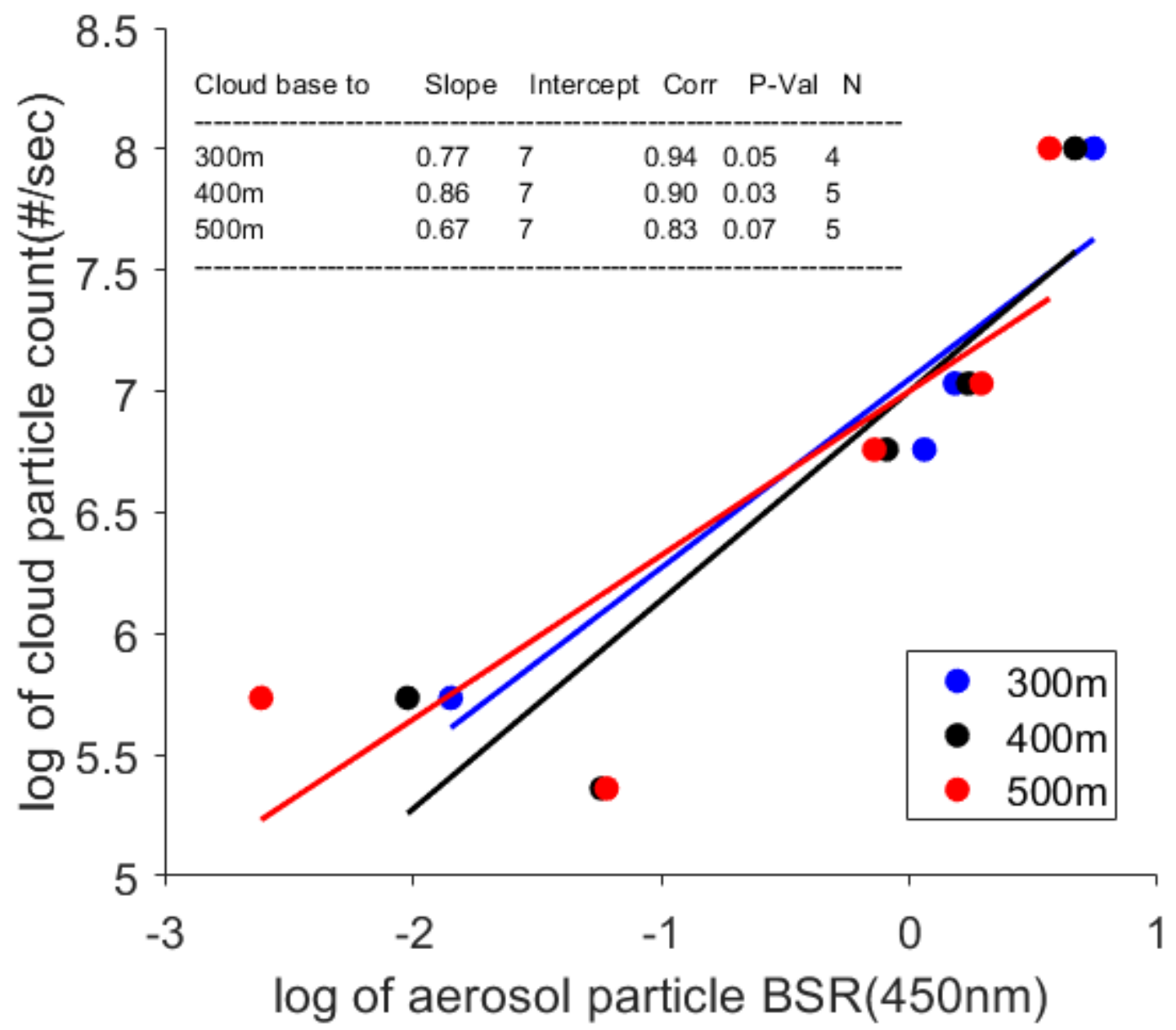

Figure 12. Scatter between logarithm values of COBALD median aerosol blue back scatter (x-axis) from 100, 200, 300, 400 and 500 meters below the cloud base and the corresponding CPS median cloud particle count (y-axis) obtained from five balloon soundings, with a linear fit (different colored lines). Table inside shows the detailed statistics. 